
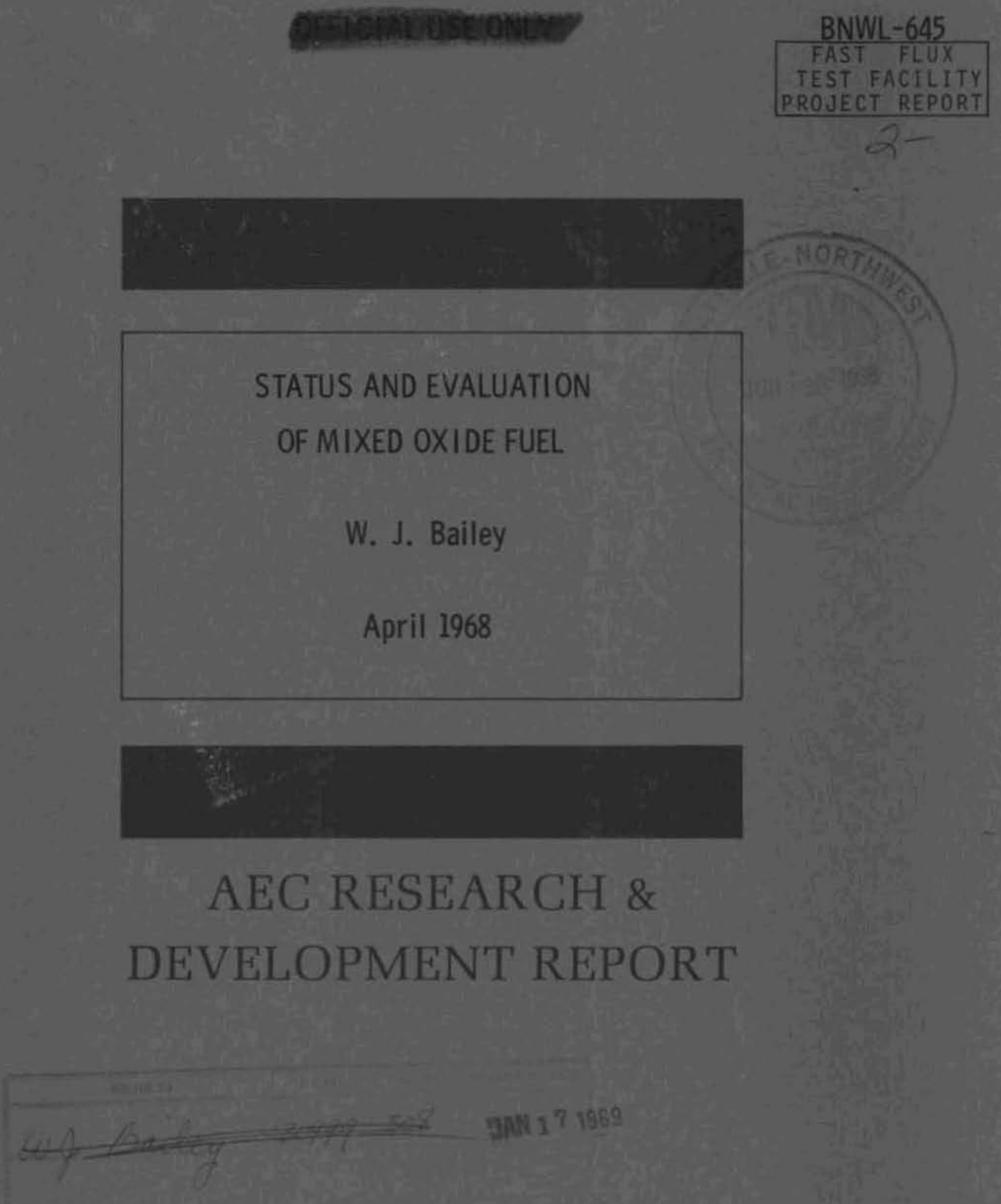

\title{
STATUS AND EVALUATION OF MIXED OXIDE FUEL.
}

W. J. Bailey

April 1968 


\section{Alamporitis}

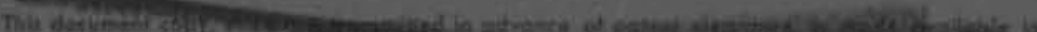

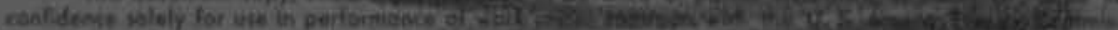

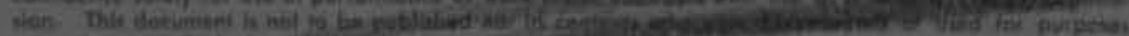

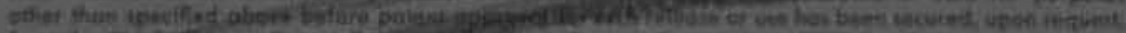

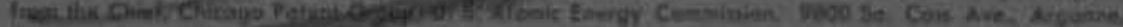
Miningh

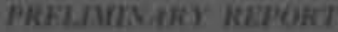

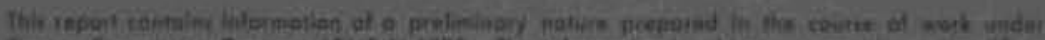

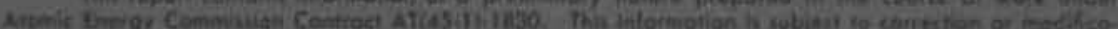

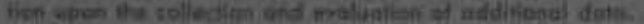

\section{L.E. II NOTEEE}

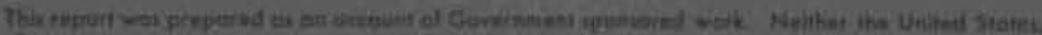

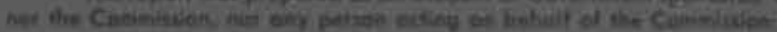

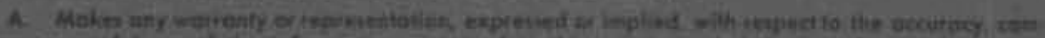

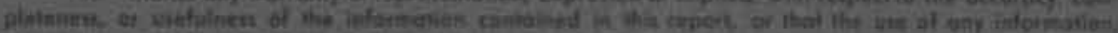

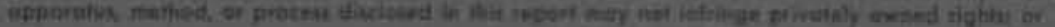

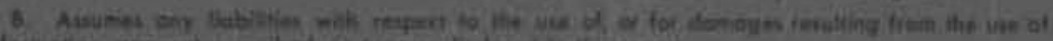

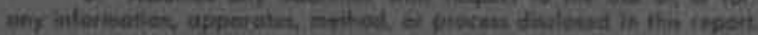

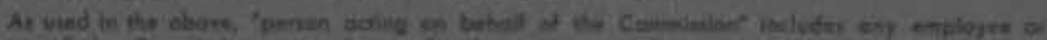

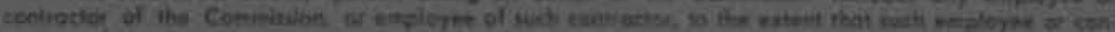

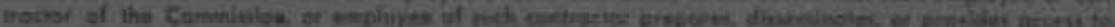

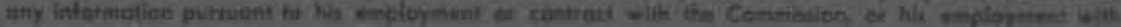
sath cantractor.

\section{PACIFIC NORTHWEST LABORATORY RICHLAND. WASHINOTOK}

operated by

BATTELLE MEMORIAL INISTITUTE

for the

UNITE STATES ATOMIC ENERGY COMMISSION UNDER CONTRACT AT(45-1)-1830 


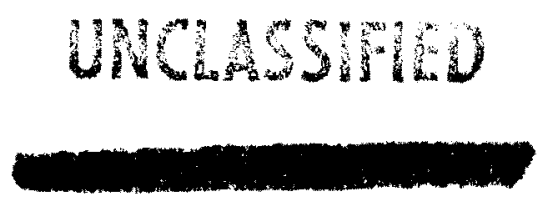

BNWL -645

33679000607392

STATUS AND EVALUATION OF MIXED OXIDE FUEL

By

W. J. Bailey

ApriI 1968

Approved by

4ricter

PACIFIC NORTHWEST LABORATORY

RICHLAND WASHINGTON

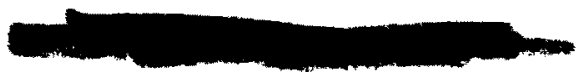

Q 


\section{TABLE OF CONTENTS}

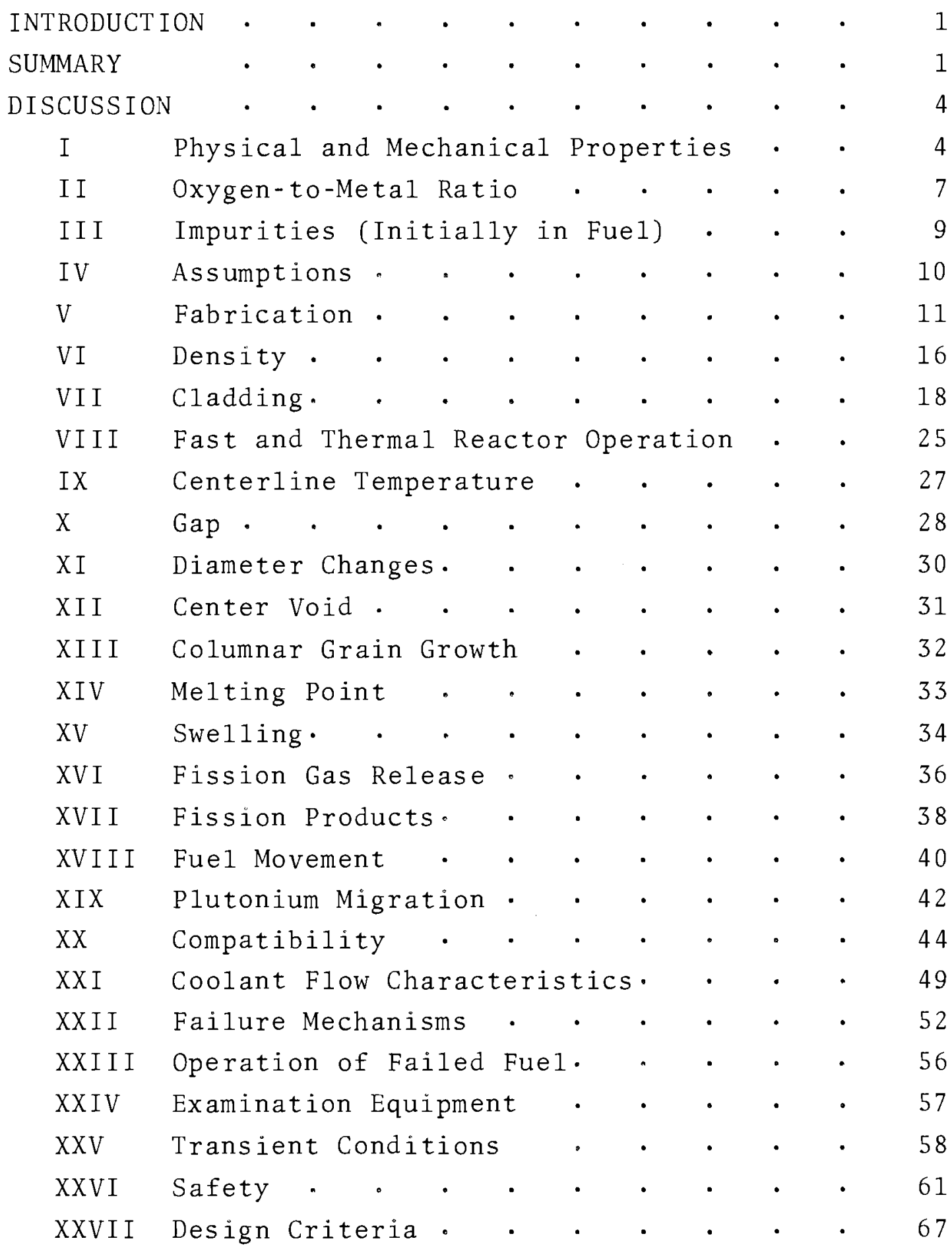




\section{TABLE OF CONTENTS (COn't)}

XXVIII Reprocessing •

XXIX Vented Fuel . . . . . . . . . . . . . 76

XXX Analytical Models. . . . . . . . . . 47

XXXI Future Design and Extrapolation Beyond

Existing Data. . . . . . . . . 79

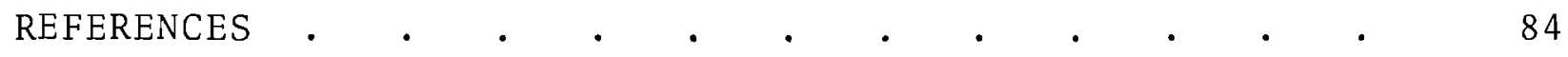




\title{
STATUS AND EVALUATION OF MIXED OXIDE FUEL
}

\author{
W. J. Bailey
}

\section{INTRODUCTION}

A survey of the literature was conducted to aid the current conceptual design work on the $\mathrm{UO}_{2}-\mathrm{PuO}_{2}$ fuel elements for the Fast Flux Test Facility (FFTF). The objective was to locate information on design, fabrication, and testing of fast reactor mixed oxide fuel elements and associated components. The period covered was from August 1965 to February 1967. This survey is an extension of the previous one included in Volume III of BNWL-CC-175.*

\section{SUMMARY}

There are a number of problem areas-many are common to thermal as well as fast reactor fuels-which must be investigated to successfully achieve certain desired improvements. Such improvements include lower fuel-cycle cost, longer fuel life, and optimization of design, process, and quality control parameters affecting reliability. ${ }^{(1,2)}$ Some of the more important items or problem areas are:

1) Almost all the presently available U.S. information on the behavior of plutonium fast reactor fuels has been obtained in capsule irradiations. (3)

2) Prototype Fast Reactor data indicate that the fuel pins are capable of reaching mean burnups in excess of $5 \%$ under PFR irradiation conditions. (4)

3) Above $7 \%$ mean burnup, fuel swelling caused pin diameters to increase, and this now appears to be the most serious problem to be overcome before $10 \%$ burnup can be reached satisfactorily. (4)

* E.R. Astley, Project Manager, Progress Report Conceptual Design Fast Flux Test Facility, BNWL-CC-175. Pacific Northwest Laboratories, Richland, Washington. August 1965. 
4) At present, no adequate theory to predict fuel swelling is known.

5) The magnitude and consequences of fue 1 swelling are not yet predictable and the effect of such safeguards as the provision of voidage in the fuel can only be determined by experiment. (4)

6) While high burnup is the target for all fast reactor fuel element designs, it is the optimum fuel cycle cost which is the real Fast Breeder Reactor target, and the many parameters involved require detailed study. (7)

7) Substoichiometric $\mathrm{UO}_{2}-\mathrm{PuO}_{2}$ appears to be the best fuel choice. $(5,4)$

8) An important problem is to determine the change in melting point of mixed oxide fuel as a function of burnup. (6)

9) No clear picture of the effect of impurities, particularly iron at the 1500 to $3000 \mathrm{ppm}$ level, has not yet emerged。(7)

10) United Kingdom (UK) data indicate that fission gas release values at $10 \%$ burnup under PFR operating conditions were:

a) vibrationally-compacted fue $1,290 \%$

b) annular pellet fue $1, \sim 50 \%$

11) The cooler portion of a pin, in which the gas retention is high, may be more vulnerable than the higher burnup sections in which gas release is enhanced. (4)

12) No evidence of significant axial fuel redistribution exists in mixed oxide operated below center melting.

13) UK workers find evidence of very substantial plutonium migration. The information is not yet sufficiently systematic to incorporate as a design equation. (4)

14) Plutonium migration radially within a PFR pin is not considered to be much of a consequence. (4) 
15) Axial migration of plutonium in PFR fuel pins may have some implications in terms of hotspots, but the main effect would be on reactivity.

16) Migration of plutonium to affect the stoichiometry of fuel could have marked effects on the irradiation behavior of fuel and on cladding/fuel compatibility.

17) It is believed that the first transient does not cause the problem of fuel pin failure but that the second transient does cause the problem. (8)

18) Very severe local coolant blockage can occur with only a small indication on mixed mean outlet temperature from a subassembly. Hence, this is potentially one of the most serious types of deterioration that may occur, first because of the difficulty of detection and second because of the difficulty of predicting the course and time scale of the sequel. (4)

19) The ultimate failure mechanism for irradiated fue 1 needs to be established. (8) 


\section{DISCUSSION}

Some of the important information obtained from the literature is included in sections I through XXXI below. The original and more detailed rough draft working notes (9) are in the FFTF File at the Pacific Northwest Laboratory.

\section{PHYSICAL AND MECHANICAL PROPERTIES}

A. RECENT ITEMS OF INTEREST:

1) GE-APD occasionally finds trace phases of $\mathrm{Pu}_{2} \mathrm{O}_{3}$ in mixed oxide fuel but finds no reason for its presence and sometimes notes it independent of stoichiometry.

2) The French note the presence of some unknown high-uranium phase in the grain boundary of Phoenix mixed oxide pellets. (10)

\section{B. PROBLEMS REQUIRING FURTHER STUDY:}

1) Need exists to study unknown high-uranium phase observed in Rapsodie mixed oxide fuel. See excerpts and/or comments from Reference 10 below:

"X-ray diffraction studies of the pellets show two phases developed during sintering. Electron probe analyses show some small crystals of some unknown high-uranium phase in the grain boundaries."

"There was no specification for maximum $\mathrm{PuO}_{2}$ particle size in the Rapsodie fuel."

2) Need exists to study the problem of setting material limitations. See excerpts and/or comments from Reference 11 below:

"In establishing a material limitation, 'statistically significant' numbers of tests are necessary. However, it is particularly dangerous to refer to statistically significant numbers of fuel rod tests, since there are very few irradiations that involve large numbers of identical rods 
irradiated under similar conditions. The water reactor systems in use today throughout the country are as close as one comes to a statistically significant test base. Even here, however, we are deficient in defining the absolute materials limitations."

3) Need exists to study second phases. See excerpts and/or comments from Reference 8 below:

"GE-APD does not find second phases, particularly sesquioxide, in hypostoichiometric fuel. They do occasionally find trace phases of $\mathrm{Pu}_{2} \mathrm{O}_{3}$ in the $X$-ray work but find no reason for its presence and they occassionally see it independent of stoichiometry."

4) Need exists to study in-reactor mechanical properties of fuels. See excerpts and/or comments from Reference 12 below:

"Tests need to be conducted at greater stresses and for longer times. More definite information is required concerning the effect of fission rate, strain rate, chemical composition, and microstructure, porosity, and pore closure, in particular."

5) Need exists to establish the cause of striations. See excerpts and/or comments from Reference 8 below: "GE-APD sees striations (cause-unidentified to date) in the microstructures of coprecipitated mixed oxides. They noted that:

(a) Striations are almost always seen in 20 wt: $\mathrm{PuO}_{2}$ mixed oxides, independent of stoichiometry (range $\sim 1.97$ to 2.01 ). 
(b) The striations may represent a stepchange in composition in the coprecipitation process.

(c) The striations are annealed out at $\sim 1400{ }^{\circ} \mathrm{C}$ in $\sim 10 \mathrm{hr}$ (in-reactor)."

6) Need exists to conduct further evaluation of the stress effect on expansion. See excerpts and/or comments from Reference 13 below:

"The thermal expansion of sintered $(\mathrm{Pu} / \mathrm{U}) \mathrm{O}_{2}$ solid solutions was determined from the measurement of X-ray lattice parameters and intensity values at elevated temperatures. Lattice shrinkage occurred in the region between 400 and $800^{\circ} \mathrm{C}$. Stress (introduced during sample preparation, during thermal cycling, or by phase transformation) considerations, with the accompanying nucleation and growth of dislocations, is the only reasonable explanation for the occurrence of this anomaly."

7) Need exists to study autoradiographic evidence. See excerpts and/or comments from Reference 8 below: "An alpha segregation or gradient is seen in molten fuel. Almost all of the characteristic microstructure changes within the fuel correlate with changes in either alpha, beta, or gamma radiography rings." 


\section{OXYGEN-TO-METAL RATIO}

A. RECENT ITEMS OF INTEREST:

1) Substoichiometric $\mathrm{UO}_{2}-\mathrm{PuO}_{2}$ appears to be the best choice. $(4,5)$

2) Both stoichiometric and hypostoichiometric mixed oxides exhibit excellent corrosion resistance in $750{ }^{\circ} \mathrm{C}$ sodium. (8)

3) Migration of plutonium could affect the stoichiometry of fuel and could have marked effects on the irradiation behavior of fuel and on cladding/fuel compatibility. (4)

\section{B. PROBLEMS REQUIRING FURTHER STUDY:}

1) Need exists to obtain and evaluate UK, PFR fuel specifications. See excerpts and/or comments from Reference 7 below:

"Process specifications have been established which enable fuel with oxygen/metal (O/M) ratios between 1.93 and 2.10 and densities up to $96 \%$ of theoretical to be achieved."

2) Need exists to continue evaluation of fuel stoichiometry. See excerpts and/or comments from Reference 4 below:

"PFR work shows that in mixed oxide, both hypoand hyperstoichiometry can occur, depending on whether the sintering atmosphere has a reducing or oxidizing potential. A consideration of the fission product spectrum from $[\mathrm{Pu}, \mathrm{U}$ (natural) $] \mathrm{O}_{2+\mathrm{x}}$ suggests that the oxide formers among the fission products may not be adequate to prevent oxygen liberation and clad attack. This would favor the use of hypostoichiometric fuel. Consequently the development studies have covered specifications from 1.93 to 2.10 O/M ratio." 
3) Need exists to continue evaluation of substoichiometric mixed oxide fuels since it appears, according to Reference 5 , to be the best choice.

4) Need exists to follow UK studies on $0 / M$ ratios. See excerpts and/or comments from Reference 7 below:

"Thermodynamic considerations by UK workers indicate that stoichiometric mixed $\mathrm{UO}_{2}-\mathrm{PuO}_{2}$ fuel is likely to be more oxidizing than $\mathrm{UO}_{2}$ at high burnup. There is a possibility that sufficient free oxygen may be available to oxidize fission product molybdenum to higher oxides than $\mathrm{MoO}_{3}$ which is easily volatile or even to permit clad attack. Consequently, if such considerations should prove to be important, a move in the direction of lower oxygen-metal ratio in fabricated fuel might prove to be beneficial. Consequently, the development studies have covered the range of composition of $0 / M$ ratio of 1.93 to $2.15 . "$

5) Need exists to study effect of $0 / M$ ratio on compatibility with the coolant. See excerpts and/or comments from Reference 14 below:

"Stoichiometric and hypostoichiometric (O/M $=1.97$ ) FCR fuel is not reduced chemically by coolant. However, some surface cracking and bulk dimensional increases were observed. The degree of observed surface cracking appeared to increase with decreasing fuel-pellet density." 


\section{I. IMPURITIES (INITIALLY IN FUEL)}

\section{A. RECENT ITEMS OF INTEREST:}

1) Impurities, in particular iron, may significantly affect the irradiation behavior (enhanced swelling may result) of mixed oxide fuel.(7)

2) No clear picture of the effect of impurities, particularly iron at the 1500 to $3000 \mathrm{ppm}$ level has yet emerged. (7)

3) Localized, oxide-type reaction was observed on the inner surface of FCR fuel pins, and the effect was attributed to attack by impurities, as yet unidentified, in the fuel. (15)

\section{B. PROBLEMS REQUIRING FURTHER STUDY:}

1) Need exists to study the effects of impurities, in particular iron. See excerpts and/or comments from Reference 7 below:

"The presence of iron can influence the sintering behaviour of the oxide and it is thought that there may be differences in irradiation behaviour. Iron additions of the level of $0.3 \%$ caused significant reductions in sintered density after sintering at $1500^{\circ} \mathrm{C}$. The presence of a mixed oxide-iron oxide eutectic liquid was observed after $\mathrm{CO}_{2}$ sintering. After hydrogen sintering, iron is present in metallic form, but in slightly oxidizing atmospheres at high temperatures these materials show large volumetric expansion due to conversion of metallic iron to ferric oxide. This point may be of significance in the irradiation behaviour of such fuel, since in the event of the development of an oxidizing environment on burn-up of ${ }^{239} \mathrm{Pu}$, enhanced swelling due to conversion of iron to iron oxide may conceivably occur." 
IV. ASSUMPTIONS

A. RECENT ITEMS OF INTEREST:

No Entries

B. PROBLEMS REQUIRING FURTHER STUDY:

Need exists to study whether substitution of ${ }^{235} \mathrm{U}$ for ${ }^{239} \mathrm{Pu}$ in irradiation tests will significantly effect fission product quantities and subsequent interactions, etc. (7) 


\section{FABRICATION}

\section{A. RECENT ITEMS OF INTEREST:}

1) PFR fuel pins employ coprecipitated mixed oxide $\left(85 \% \mathrm{UO}_{2}, 15 \% \mathrm{PuO}_{2}\right.$ ) fuel and 316 SS cladding.

2) PFR fuel pins used coprecipitated mixed oxide because of requirements of homogeneity and ease of reprocessing.

3) Fast reactor fuels pose shielding and binderdegradation problems due to the presence of alpha and gamma activity and neutrons, but none of these has been found in PFR studies to present unacceptable difficulties. (4)

4) PFR studies indicate that wrapper (similar to FFTF subassembly duct) specifications have yet to be achieved in practice. (4)

5) In fabrication of packed powder fuel, it was difficult to restrict gas release to a specific limit. (17)

6) Water inside the fuel rod significantly alters the irradiation performance of a fuel rod in a thermal flux spectrum. (18) Data may not be applicable to the fast flux case.

7) Although standard BWR fuel is fabricated from sintered $\mathrm{UO}_{2}$ pellets, the vibratory compaction process offers potentially lower fabrication costs. Several hundred packed powder rods are under irradiation in the Dresden, Big Rock Point, and JPDR reactors, and so far, pellet and powder fuel have performed equally well. (19) 
B. PROBLEMS REQUIRING FURTHER STUDY:

1) Need exists to conduct further study on costs of fabricating fuel with plutonium recycled from power reactors (as well as from FFTF). One study indicated incremental cost of only 2 to $3 \%$ of cost using low-exposure plutonium. (20)

2) Need exists to study evidence that higher water content can be tolerated in stainless steel-clad oxide fuel. (21)

3) Need exists to study problem of meeting the allowable gas release limit with vibrationally compacted fuel.

4) Need exists to evaluate the use of an automatic inspection system. See excerpts and/or comments from Reference 22 below:

"The automatic system, used during post-run examination of Phoebus and NERVA reactor fuel, could replace the tedious visual examination of the exteriors of large numbers of highly radioactive fuel elements. The length of the element is covered in each view by two photographs that provide a permanent film record of flaws on each element as small as 0.005 in. Films have been used months after completion of a disassembly to check new ideas about corrosion processes."

5) Need exists to study the problems involved in shifting from oxide to carbide fuel. See excerpts and/or comments from Reference 7 below:

"The main PFR development work has been on mixed uranium-plutonium oxide fuel, but the possibility of replacing oxide by carbide has been taken into account in flow-sheeting the plant." 
6) Need exists to conduct further studies on choice of fabrication routes. See excerpts and/or comments from Reference 7 below:

"In the UK work on $\mathrm{PFR}$, the requirements of homogeneity for physics specifications and considerations of ease of reprocessing led to a co-precipitation route rather than of physical mixing of uranium and plutonium oxides. Evidence has been adduced that single phase solid solutions were more easily prepared by the former route and no problems were likely to arise from the presence of nitric acid insoluble plutonium compounds when reprocessing irradiated fuel. This is clearly attractive since conventional constructional material can be employed in the absence of fluoride catalysed dissolutions normally required for plutonia."

7) Need exists to study problem of pellet quality control. See excerpts and/or comments from Reference 10 below:

"Chemical analyses of French pellets often did not agree with the weighed amount of materials used. Americium causes a systematic error in the coulometric determinations."

8) Need exists to further evaluate choice of fuel manufacturing route. See excerpts and/or comments from Reference 4 below:

"The three major considerations which conditioned the UK choice of PFR manufacturing route were:

a) What was the most convenient starting material from overall consideration, nitrate 
solution or a solid (e.g., plutonium dioxide): consideration of existing plant, forward total reactor programme, storage and transport prob1 ems are germane to this choice.

b) Which of the available routes best satisfied physics specifications for homogeneity of the fue 1.

c) Which route led to the simplest reprocessing route consistent with the optimum usage of available technology and plants.

The choice made is dependent on the particular circumstances of a manufacturer as well as on purely technical grounds. UK experience, plant availability, the view taken of meeting physics requirements and the desirability of avoiding hydrofluoric acid in reprocessing (with associated problems of increased active waste storage), led to the choice of coprecipitation of mixed oxide from uranyl-plutonium nitrate solution with ammonia, with filtration and drying of the ADU-plutonium hydroxide precipitate and calcination and reduction to ( $\mathrm{Pu}, \mathrm{U})_{2}$. Mixed carbide is produced by a further step of carbothermic reduction of the oxide. Physical mixing of the oxides is regarded as perfectly feasible and may well be adopted in the UK in the longer run."

9) Need exists to continue evaluation of UK fuel forms. Two PFR fuel forms have been considered: annular pellets and vibrationally compacted fuel. (4)

10) Need exists to study dosage, shielding, and processing problems. See excerpts and/or comments from Reference 4 below: 
"Special problems are highlighted in fast reactor fuels due to the presence of $\alpha$ and $\gamma$ activity and neutrons. These pose shielding and binder-degradation problems, none of which has been found to present unacceptable difficulties."

11) Need exists to conduct refabrication studies. See excerpts and/or comments from Reference 23 below:

"The economics of refabricating bred fuel from converter and breeder reactors is one of the principal questions in nuclear technology yet to be demonstrated. Such fuels require that the operators be protected from penetrating radiation during the fabrication process."

12) Need exists to evaluate more recent data and see if the following statement is still true. In July 1965, the AEC indicated that no clear cut advantage, either in cost or performance, has been shown between impacted, coprecipitated, or mechanically mixed material. (6) 


\section{DENSITY}

\section{A. RECENT ITEMS OF INTEREST:}

1) Control of density in the preparation of low density pellets was the most serious problem encountered in one program, (24)

2) Simple low density pellets (no additions) did not survive subsequent centerless grinding and handing operations. (24)

3) PFR annular pellet and vibrationally-compacted fuel pins have a smear density of approximately $80 \%$ TD. (4)

B. PROBLEMS REQUIRING FURTHER STUDY:

1) If low density pellets are considered, the density control problem needs to be resolved. (24)

2) Need exists to evaluate density, stoichiometry, and impurity requirements. See excerpts and/or comments from Reference 7 below:

"The sintering of mixed oxides is conditioned by the requirements of specified density and stoichiometry and by impurity levels (particularly of iron). Process specifications for PFR fuel have been established which enable fuel with $0 / \mathrm{M}$ ratios between 1.93 and 2.10 and densities up to $96 \%$ of theoretical to be achieved."

3) Need exists to study allowable density variations if packed powder pins are considered. It has been found that density variations within $\pm 2 \%$ of the mean can be achieved in PFR pins, with a local larger end variation up to about $5 \%(4,7)$

4) Need exists to study void incorporation. If one is to reach desirable goal values, alternate modes of void 
volume incorporation need to be considered. These modes are filled with experimental unknowns.

5) Need exists to establish void distribution method. See excerpts and/or comments from Reference 8 below:

"One needs a certain void fraction within the fuel for the transient melting case, as we11 as fuel swelling. The void can be distributed in the following ways:

a) use a radial gap,

b) use annular pellets,

c) use low density pellets, or

d) use packed powder fuel.

Of the possibilities, GE-APD has not made a choice; however, their reference design employs a radial gap. GE-APD finds that gap size very definitely controls the center temperature initia11y.

A fuel element with a smear density of $90 \%$ of theoretical could accomodate $75 \%$ of the fuel in the molten state."

6) Need exists to study annular fuel behavior. GE-APD has irradiated annular pellet fuel and they do not see any disadvantage as was recorded in the LSBR data on the use of annular fuel. (8) 


\section{CLADDING}

A. RECENT ITEMS OF INTEREST:

1) PFR studies on cladding show that the effects of a high fast flux on creep rates are virtually unexplored.

2) No information on the effect of nuclear irradiation on metals under dynamic creep or fatigue loading is available. (26)

3) PFR cladding studies indicate that creep strength, yield strength, ductility, and corrosion resistance in clad. materials are the major requisites. (4)

4) PFR cladding studies indicate that the strain, over the majority of the pin dwell time, is very small and then it builds up very rapidly. (4)

5) On failed PFR pins, both transgranular and intergranular cracks were observed in cladding.

6) With cladding, nitrogen and boron reactions (producing helium) are more important in fast reactors than has been generally accepted. (27)

7) UK workers indicate that high quality stainless steel tubing can be obtained to meet a tight specification. This is not the case yet with nickel base alloys. (4)

B. PROBLEMS REQUIRING FURTHER STUDY:

1) Need exists to evaluate the cause for high strains (one to two orders of magnitude more than predicted) in pin cladding. Is this due to fuel swelling? (16)

2) Need exists to study high-burnup Yankee fuel rods. See excerpts and/or comments from Reference 28 below: 
"Unusually large, elongated grains were noted along several crack interfaces in the SS-clad $\mathrm{UO}_{2}$ fuel rods. The duplex nature of the observed reaction zone (on inner surface) needs to be studied."

3) Need exists to evaluate helium production in cladding, reduce errors in estimates, and examine cladding specifications. (27)

4) Need exists to study cracking problems if extruded fins are to be considered instead of wire wraps. See excerpts and/or comments from Reference 10 below:

"Cracks were noted by the French at the base of extruded fins. These were undetectable nondestructively except through the use of dye penetrant."

5) Need exists to conduct more nondestructive testing (NDT) studies. See excerpts and/or comments from Reference 10 below:

"Nondestructive tests of welded French fuel pins were difficult. Helium leak test was shown to be very poor with sodium-bonded dummy pins because sodium tends to plug leaks and shows up many months later as soda on the outside of the cladding."

6) Need exists to study closure controls. See excerpts and/or comments from Reference 4 below:

"The philosophy has been adopted for PFR that failure should not occur in a closure before it would occur in the body of the tube. This has generated a program of investigation of brazing, welding, and forming closures in clads of varying heat treatments. An additional desideratum 
is that the process adopted should enable manufacture to proceed essentially on a process control basis rather than by refined inspection of the product."

7) Need exists to follow UK work on cladding specifications. See excerpts and/or comments from Reference 4 below:

"At present, high quality stainless steel tubing can be obtained for PFR pins meeting a tight specification. This is not yet the case with nickel base alloys, which are less highly developed, but no intractable problems are recognized."

8) Need exists to study problems involved if a reduceddiameter section is considered on the fuel pin. See excerpts and/or comments from Reference 4 below:

"In the PFR design, the tubing is drawn down to a minor diameter over the plenum length to reduce pressure drop. This complicates the empty can route, but is a practical proposition."

9) Need exists to study stress problems with packed powder pins during compaction. See excerpts and/or comments from Reference 29 below:

"A tremendous amount of energy must be imparted to ORNL fuel tubes in the axial direction to obtain acceptable compaction results; severe stresses will be experienced in much of the machine as well as in the fuel tube itself. Therefore, particular attention had to be paid to the method of grasping and supporting the fuel tube during the compaction cycle to prevent structural failure of the tube."

10) Need exists to study the fuel cladding assurance prob$1 \mathrm{em}$. See excerpts and/or comments from Reference 11 below: 
"Assurance of quality of fuel cladding is dependent on obtaining a meaningful definition of mechanical property requirements, such as multiaxial ductility under combined operating stresses, and fatigue life necessary under anticipated pressure cycling. The implications to fuelelement design are unclear, since requirements vary depending on the fuel-element configuration and the reactor operating conditions. Fortunately, conservative cladding design and frequent inspections serve to lessen the problems, however, these are costly approaches and should be viewed as an interim measure."

11) Need exists to study the effect of carbon on the cladding. See excerpts and/or comments from Reference 30 below:

"Carbon absorption causes severe loss of ductility in both materials ( 304 and $316 \mathrm{SS}$ ), but the structural instabilities and variability of ferrite volume in 304 adds to the problem of scatter in the data. The structural damage which can occur in these materials due to carbon absorption must be considered an important point of design of liquid-metal-cooled reactor systems."

12) Need exists to study sintering of stainless stee1 directly exposed to flowing sodium. See excerpts and/or comments from Reference 31 below:

"In OFBRE studies, 316 SS did not sinter and sintering of air-oxidized 304 SS was much less than that of pure 304 SS (however, the oxide film was completely removed during the run). While the mass transfer and decarburizationcarburization problems with stainless steels 
are well known, the parameters and the magnitude of the parameters are not clearly defined."

13) Need exists to study the corrosion loss with stainless steel in dynamic sodium. See excerpts and/or comments from Reference 4 below:

"In PFR tests with stainless steel, the rate of loss is sensitive to oxygen content and broadly insensitive to velocities above $10 \mathrm{fps}(3.0 \mathrm{msec})$, With high nickel content alloys (approximately $80 \%$ ), the rate of loss is sensitive to velocity and is regarded as marginally too high for PFR. With intermediate nickel content, (PE16, 43\% Ni) the cladding behaves more like stainless steel. It remains to check that the data are valid for fuel elements in rigs more analogous to a reactor circuit in size and construction. Test results of carbon pickup show that at $650^{\circ} \mathrm{C}$, surface carbon in stainless steel can increase from $0.02 \%$ to $0.2 \%$ in a few months. The implications of these results on fuel element performance remain to be clarified. Loss of high temperature ductility must certainly be expected, but at present no very serious degradation of pin cladding performance can be predicted from this phenomenon."

14) Need exists to establish clad-stress criteria. See excerpts and/or comments from Reference 32 below:

"Two criteria are conventional limits related to thermal-stress fatigue failure and primary stress, respectively. A third is a conservative limitation on the combination of the thermal stress and pres. sure stress. Due to the relatively high clad tem. peratures, it was found in UNC carbide pins that 
the creep criterion is limiting for the 0.015 and $0.020-i n$. clad specimens. For the 0.030-in. specimens, the thermal-stress criterion is limiting."

15) Need exists to follow UK work on cladding. See excerpts and/or comments from Reference 4 below: "The PFR development studies have been restricted to two fuels, mixed oxide and mixed carbide; and two types of canning materials, austenitic stainless steels of the 316 type and precipitation hardening nickel-base alloys, principally pe16. Creep strength, yield strength, ductility and corrosion resistance in clad materials are the major requisites. Significant loss of high temperature tensile ductility may occur. Effects of a high fast flux on creep rates are virtually unexplored. Significant section loss will occur in these materials at the hotter end of PFR pins due to coolant corrosion. These authors and Russian workers find that less corrosion occurs at approximately $700{ }^{\circ} \mathrm{C}$ in nickel-base alloys with lower nickel contents, and that the best of them is comparable with austenitic stainless steels as regards section loss."

16) Need to follow thermal reactor cladding results. See excerpts and/or comments from Reference 33 below: "GE-San Jose reports that stainless steel cladding is susceptible to cracking above $\sim 7500$ MWd/tonne in $\mathrm{UO}_{2}$ irradiations in thermal reactors. The cracking is related to operating stresses. They also observe intergranular corrosion in the water coolant." 
17) Need exists to study strain cycling. See excerpts and/or comments from Reference 3 below:

"The high power density in the fuel leads to correspondingly large radial temperature gradients and the fuel cladding must withstand strain cycling at high cladding temperatures in sodium. (In FBR design studies, this environment includes exposure for as long as 3 years or more at temperatures near $600{ }^{\circ} \mathrm{C}$, and to fast neutron flux dosages up to $3 \times 10^{23}$ neutrons/ $\mathrm{cm}^{2}$ or more)."

18) Need exists to obtain dynamic creep or fatigue loading data. See excerpts and/or comments from Reference 26 below:

"To the writers' best knowledge, no information on the effect of nuclear irradiation on metals under dynamic creep or fatigue loading is available, although such knowledge is essential to the proper design of nuclear reactors from the viewpoint of stress analysis. By comparing the stress-range diagrams for the pre- and postirradiation (for aluminum), one can see the shifting in position of the ductile-brittle transition line by nuclear irradiation. An analytical model is suggested that will represent the creep rupture and fatigue strength of metals with the effect of neutron irradiation." 
VIII. FAST AND THERMAL REACTOR OPERATION

\section{A. RECENT ITEMS OF INTEREST:}

1) Almost all the presently available U.S. information on the behavior of plutonium fast reactor fuels has been obtained in capsule irradiations.

2) UK data include information on PFR subassembly tests in DFR. PFR pins operate at ratings to $250 \mathrm{~W} / \mathrm{cm}(\sim 9 \mathrm{~kW} / \mathrm{ft}$ average, $\sim 14 \mathrm{~kW} / \mathrm{ft} \max$.$) .$

3) GE, FCR experiments pertain mainly to the $15-20 \mathrm{~kW} / \mathrm{ft}$ range. ${ }^{(8)}$

4) Assemblies of highly rated fuel pins have a strong tendency to the rmal bowing instability.

5) The physical behavior (size of central void and degree of melting) of packed powder fuel in long rods operating at high power generating conditions varies noticeably.

B. PROBLEMS REQUIRING FURTHER STUDY:

1) Need exists to study ways (e.g., in a fast reactor use high leakage core and degraded spectrum) to increase the time before either boiling or burnout occurs, since this is very important according to GE-APD.

2) Need exists to follow BWR fuel design studies. See excerpts and/or comments from Reference 1 below:

"The trend in BWR fuel design is to higher core power and longer fuel life. Burnable poisons (e.g., erbia and gadolinia) will be employed. Lower material and fabrication costs will be a major source of improvement in BWR fuel-cycle costs. One such improvement is the use of Zircaloy fuel-rod spacers to enhance neutron economy in the core. Vibratory compaction offers potentially lower fabrication costs. Plutonium generated in BWR cores will be 
recycled for optimum fuel-cycle economy. There is a need to develop an economical fabrication technique for the plutonium fuels. There is also a need to explore alternate methods for use of plutonium in a BWR core."

3) Need exists to follow development work on fuel elements for nuclear superheat. See excerpts and/or comments from Reference 35 below:

"Integral nuclear superheat offers new possibilities of further basic improvement for the directcycle boiling reactor. The superheating fuel element is the key item in this development."

"Operation of experimental superheating reactors, although not yet far enough along to prove fuel element lifetime, has demonstrated the essential fact that although defects in oxide-fueled superheat elements cause operational inconvenience, they do not cause prohibitive radioactive contamination of the steam; successful fuel-element performance has been experienced to date." 


\section{CENTERLINE TEMPERATURE}

\section{A. RECENT ITEMS OF INTEREST:}

1) Center fuel temperature knowledge is needed to realize the full potential of any design, (36)

2) The continuous measurement of center fuel temperatures in mixed oxide fast reactor pins presents its own peculiar problems with 1ittle, if any, past experience to help in the solution. (36)

3) The high temperatures to be measured necessitate the exclusion of the usual well tried thermocouples and enforce the use of exotic materials that are both difficult to handle and have not been fully characterized.

4) $\mathrm{A} U K$ instrumented $\mathrm{UO}_{2}-\mathrm{PuO}_{2}$ pin experiment in DFR continued to give fuel center temperatures after 14 weeks irradiation.

5) UK tests show that the fuel center temperature increases to a maximum after about 17 days and then falls steadily.

B. PROBLEMS REQUIRING FURTHER STUDY:

1) Knowledge is needed on the continuous variation of temperature (e.g., fuel center, cladding) in order to optimize design and realize fuel potential. (36)

2) Information on fuel center temperature variation is also useful in predicting the physics of the reactor system.

3) There is a need to study the problem of continuously measuring fuel center temperatures. There is little, if any, past experience to help in the solution. (36)

4) The cause and magnitude of the temperature rise in the fue 1 pin during the first few days of operation needs to be studied. Is the subsequent drop in fuel temperature due to fuel swelling? (36) 


\section{$X . \quad$ GAP}

A. RECENT ITEMS OF INTEREST:

1) Of four possible ways to distribute the void in mixed oxide fuel, a choice has not been made by GE-APD; however, their reference design employs a radial gap. (8)

2) GE-APD data suggest that while the gap size is important at the start of irradiation, it tends to decrease as a function of time, and that tight dimensional tolerances on pellets and cladding may not be necessary.

3) If, for safety, it is necessary to design a sodium-bonded ceramic fuel element with a low heat rating so that loss of liquid metal bond can be tolerated without cladding failure, there is a strong incentive to specify a gasbonded element from the start.

B. PROBLEMS REQUIRING FURTHER STUDY:

1) Need exists to study the effect of gap on pellet and cladding tolerances. While the gap size is important at the start of irradiation, it tends to decrease as a function of time and tight dimensional tolerances on pellet and cladding may not be necessary. (3)

2) Need exists to further evaluate evidence that gap decreases as a function of time at power and number of thermal cycles. (3)

3) Need exists to further evaluate gap coefficients and thresholds (for fuel-clad mechanical interaction effects). See excerpts and/or comments from Reference 37 below:

"Many prior results have been subject to large quantitative uncertainties because of limitations in ability to control experimental conditions. Recent studies indicate that a 4 to 10 mil gap decreases to about one-half its initial value." 
4) Need exists to study gas-gap variations. See excerpts and/or comments from Reference 38 below:

"SNAP fuel studies indicated that because of the gas-gap variation (in example case), asymmetry of a fuel rod greatly increases the fuel-surface temperature variation. However, the cladding variation is increased only slightly, and the maximum fuel temperature is actually reduced from the symmetric case. Although these results are strictly valid only for the specific geometry of the SNAP-8 reactor, the analytic techniques and general conclusions are applicable to other liquid-metal cooled reactors with tightly packed bundles of elements." 


\section{DIAMETER CHANGES}

A. RECENT ITEMS OF INTEREST:

GE tests in EBR-II show slight ridging at pellet interfaces in pellet fuel but show no ridging in vibrationally compacted pins.

B. PROBLEMS REQUIRING FURTHER STUDY:

1) Need exists to study the problem of uncertainty in diameter measurements on irradiated pins. (16)

2) Need exists to study the influence of cracks on diameter increase on failed pins. (16)

3) Need exists to evaluate the possibility that the resistance to deformation of the cladding in pellet fuel pins is, initially, considerably greater than that of the internal fuel surface. (4)

4) Need exists to investigate whether it is feasible that the can yields progressively under slightly increasing stress - as swelling stresses increase - rather than creeps under a uniform stress. (4)

5) Need exists to study evidence that the fuel is plastic and that fuel strain may be directed inwards by a reasonably strong can.

6) Need exists to evaluate ridging problem. See excerpts and/or comments from Reference 37 below:

"Randomly occurring 0.1 to $0.3 \mathrm{mil}$ ridges were measured on the cladding at pellet interfaces on GETR test pins run at 19 to $22 \mathrm{~kW} / \mathrm{ft}$. The ridges were independent of gap size. Much larger ridges are commonly observed in watercooled reactor tests with $\mathrm{UO}_{2}$ in 0.5 in. diameter fuel rods. This suggests that the higher fuel-surface temperature for fast-reactor test conditions, and/or the use of mixed $\mathrm{Pu}-\mathrm{U}$ oxide fuel, increases the plasticity of the fuel." 
XII. CENTER VOID

A. RECENT ITEMS OF INTEREST:

1) The size of the central void formed in packed powder fuel at and above columnar grain-growth temperatures is not necessarily related to the rod power or degree of fuel melting during operation in a long fuel rod. (39)

2) UK tests indicate occasional deviation of central void from pin axis in packed powder fuel pins.

B. PROBLEMS REQUIRING FURTHER STUDY:

Need exists to study the effect of deviations of central void in vibrationally compacted fuel pins with respect to pin axis. 
XIII. COLUMNAR GRAIN GROWTH

\section{A. RECENT ITEMS OF INTEREST:}

No entries.

B. PROBLEMS REQUIRING FURTHER STUDY:

Need exists to study effect of change in columnar grain zone diameter (it reaches a maximum value then begins to contract as irradiation continues). (16) 


\section{MELTING POINT}

\section{A. RECENT ITEMS OF INTEREST:}

1) Hypostoichiometric, $\mathrm{UO}_{2}-20 \% \mathrm{PuO}_{2}(\mathrm{O} / \mathrm{M}=1.972)$ melted at $2880 \pm 10{ }^{\circ} \mathrm{C}$, nearly $100^{\circ} \mathrm{C}$ higher than stoichiometric $\mathrm{UO}_{2}-20 \% \mathrm{PuO}_{2} \cdot(40)$

2) Recent data reinforce the viewpoint that, regardless of burnup, the initial termination of porosity moving radially inward is the outer limit of melting, i.e., the outside edge of the high density band.

B. PROBLEMS REQUIRING FURTHER STUDY:

1) Need exists to study the limit of melting in mixed oxide fuel. Significant disagreement exists among workers at different laboratories concerning the limit of melting in irradiated $\mathrm{UO}_{2} \cdot(42)$

2) Need exists to study the very important problem of change in melting point of mixed oxide fuel as a function of burnup. (6) 


\section{SWELLING}

A. RECENT ITEMS OF INTEREST:

1) At present, no adequate theory to predict fuel swelling is known.

2) The UK workers indicate that the magnitude and consequences of fuel swelling are not yet predictable, and the effect of such safeguards as the provision of voidage in the fuel can only be determined by experiment. (4)

3) Quantitative swelling data on oxides are sparse, and controlled test conditions are very difficult to attain. $(8,43)$

4) Swelling data on mixed oxides are substantially lower than prior data on $\mathrm{UO}_{2}$. (43)

B. PROBLEMS REQUIRING FURTHER STUDY:

1) The problem of big scatter in the swelling data needs to be resolved. ( 8 )

2) Quantitative data on irradiation-induced swelling patterns versus temperature and degree of restraint are required for rational design of high burnup fuels. (43)

3) Reliable quantitative data on gas release and swelling on oxides are sparse and controlled test conditions are very difficult to attain. (43)

4) Is the swelling rate for mixed oxide less than that for $\mathrm{UO}_{2}$ for conditions other than strong lateral restraint? (43)

5) Fuel swelling properties of pellet fuel and vibrationallycompacted fuel may be different at high burnup (e.g. 10\%).

6) Need exists to evaluate fuel swelling. The magnitude and consequences are not yet predictable, and the effect of safeguards such as the provision of voidage in the fuel can only be determined by experiment. (4)

7) Need exists to evaluate this concept. In vibrationallycompacted fuel, the fuel swelling due to the growth of 
bubbles of fission gases gradually absorbs inter-particle porosity and brings about pressure bonding of fuel/fuel and fuel/clad contact surfaces. (4)

8) Need exists to study the swelling problem. See excerpts and/or comments from Reference 32 below:

"The principal problem of a fuel pin that contains either oxide or carbide fuel is accommodation of swelling. A large radial gap is not feasible without excessive fuel temperature. Accommodation of swelling is therefore sought through clad restraint and internal accommodation using several distributions of voids within the fuel."

9) Need exists to develop fuel swelling models. GE-APD feels that it is very important that fuel swelling models, which may actually work for water-cooled reactors (fuel surface temperature of approximately $400^{\circ} \mathrm{C}$ ), are not necessarily applicable to sodium cooled tests where fuel surface temperature is closer to $1000^{\circ} \mathrm{C} .(8)$

10) Need exists to study stresses and strains in irradiated fuel. Because of irradiation growth and swelling, the strains are greater and the stresses are flatter in irradiated material than those produced in a nonirradiated material. (72) 
XVI. FISSION GAS RELEASE

\section{A. RECENT ITEMS OF INTEREST:}

1) UK data indicate that probable fission release values at $10 \%$ burnup under PFR operating conditions are:

a) vibrationa11y compacted fuel: $\sim 90 \%$

b) annular pellet fuel: $\longleftarrow 50 \%$.

2) FCR pin tests in EBR-II indicate 7\% fission gas release with high density ( 87 to $95 \%$ TD) fuel and to $25 \%$ release in low density ( $85 \%$ TD) vibrationa $11 y$ compacted fuel. ( 15 )

3) The cooler portion of a pin, in which the gas retention in high, may be more vulnerable than the higher burnup sections in which gas release is enhanced.

4) Little fission gas is released from the fuel during steady reactor operation; most of the gas in the hottest region is released during a power cycle. (44)

5) Size and degree of dispersion of bubbles or the stress distribution during transients may influence the measured gas releases and may partly explain the poor reproducibility reported for fission product gas releases. (44)

B. PROBLEMS REQUIRING FURTHER STUDY:

1) Use of fuels in which the gas retention is high may reduce the probability of failure by the fission gas pressure mechanism only at the risk of premature failure as a result of fuel swelling. (4)

2) Need exists to evaluate fission gas release at high burnup. Predicted values are approximately 90\% for vibrationallycompacted fuel and approximately 50\% for annular pellet fuel at $10 \%$ burnup. (4)

3) Need exists to study effect of power cycling on fission gas release, since evidence indicates most of the gas is released during sucil times. (44) 
4) The size and degree of dispersion of bubbles (which may be affected by fuel structural changes) or the stress distribution during transients may influence the measured gas releases and may partly explain the poor reproducibility reported for fission-product gas releases. (44)

5) Need exists to remotely measure fuel swelling and gas pressure buildup. (45)

6) Need exists to study gas permeability in mixed oxide fast reactor pins. $\mathrm{B} \& \mathrm{~W}$ data on $Z$ ircaloy-clad $\mathrm{UO}_{2}$ rods indicated that theoretically predicted gas flow could not be achieved. A literature search by $B \& W$ revealed a lack of gas permeability data for nuclear fuel materials, particularly for helium and fission gases. (73) 


\section{FISSION PRODUCTS}

\section{A. RECENT ITEMS OF INTEREST:}

1) A marked difference in axial movement of fission products was noted between vibrationally compacted and pellet pins. (7)

2) UK workers observe smaller segregates in pellet pins than in packed powder pins. (4)

3) An unusual effect, a high concentration of fission products at the extreme outer sintering boundary, seems to be unique to mechanically mixed $\mathrm{UO}_{2}-\mathrm{PuO}_{2}$ fuels. (39) Cause of the effect has not yet been determined.

4) Localized, oxide-type reaction was observed on the inner surface of FCR fuel pins, and the effect was attributed to attack by impurities, as yet unidentified, in the fuel. (15)

B. PROBLEMS REQUIRING FURTHER STUDY:

1) How significant is the difference in fission product migration in annular pellet pins versus vibrationallycompacted pins? ${ }^{(7)}$

2) Unusual effect noted on radial fission product migration in mechanically mixed. $\mathrm{UO}_{2}-\mathrm{PuO}_{2}$ fuels needs to be studied.

3) Localized inner cladding surface reaction product needs to be evaluated to correlate effect with burnup and identify impurities which may cause the effect. (15)

4) Need exists to study why segregates tend to be smaller in irradiated pellet pins than in vibrationally compacted pins. (4)

5) Need exists to study fission product migration in fuel pins. It is not known in detail to what extent this 
migration and condensation will occur, nor to what extent solid compounds of cesium will be formed. (4)

6) Need exists to study inclusion observations in more detail. Metallic inclusions were observed in the central zone of the coprecipitated and mechanically blended substoichiometric specimens, while no such inclusions were detected in mechanically blended stoichiometric material. (46) 


\section{FUEL MOVEMENT}

\section{A. RECENT ITEMS OF INTEREST:}

1) No evidence of significant axial redistribution exists in mixed oxide operated below center melting.

2) Both upward and downward movement of fuel are noted as a result of transient melting in irradiated mixed oxide tests. ${ }^{(8)}$

3) There is convective mixing of molten fuel.

4) PFR fuel pins have compartments to restrict fuel redistribution and to locate fuel segment-wise with respect to the can. (4)

5) Two methods (choice not made yet) are being evaluated for locating the fuel in PFR pins.

6) There is evidence of flow of liquid fuel into radial cracks that existed during operation - a previously unobserved phenomenon. (39)

B. PROBLEMS REQUIRING FURTHER STUDY:

1) The effect of convective mixing of molten fuel needs to be studied. (47)

2) Need exists to study the PRTR high-power-density program. See excerpts and/or comments from Reference 34 below:

"Tests with packed powder mixed oxide fuel indicate axial relocation of fuel (also occurs with pellet fuel) when fuel operated under molten conditions. Variations in size of central void and degree of melting have been observed in packed powder rods operating at high power generating conditions. Convective mixing noted within the molten oxide in long fuel rods." 
3) Need exists to study fuel location problem. See excerpts and/or comments from Reference 4 below:

"Two considerations in the location of fuel in PFR pins arose. Firstly, a datum must be established in the pin for controlling the position of the column as loaded, and therefore the core reactivity worth; secondly, the PFR design has compartments within the fuel column both to restrict redistribution, and to locate the fuel segment-wise with respect to the can. This latter requirement is of a somewhat conjectural nature, but may result in a very material lessening of peak temperature in a transient resulting from pump run-down." 
XIX. PLUTONIUM MIGRATION

\section{A. RECENT ITEMS OF INTEREST:}

1) UK workers find evidence of very substantial plutonium migration. The information is not yet sufficiently systematic to incorporate as design equation. (4)

2) Plutonium segregation has been observed in mixed oxide pins irradiated at high performance limits. (47)

3) Plutonium migration radially within a PFR pin is not considered to. be much of a consequence. (4)

4) Axial migration of plutonium in PFR fue 1 pins may have some implications in terms of hotspots, but the main effect would be on reactivity. (4)

5) Migration of plutonium could affect the stoichiometry of fuel and could have marked effects on the irradiation behavior of fuel and on cladding/fuel compatibility. (4)

B. PROBLEMS REQUIRING FURTHER STUDY:

1) Need exists to study plutonium migration, since it could have both physics and metallurgical implications on fuel element performance. (4)

2) Need exists to follow the UK work on plutonium migration. See excerpts and/or comments from Reference 4 below:

"Evidence has been found in the PFR program of very substantial plutonium migration (down to $50 \%$ of initial concentration). The information is not yet sufficiently systematic to incorporate as a design equation."

3) Need exists to study plutonium migration. See excerpts and/or comments from Reference 4 below:

"Plutonium migration radially within a PFR pin is not considered to be of much consequence. 
Axial migration of plutonium may have some implications in terms of hotspots, but the main effect would be on reactivity. The migration of plutonium to affect the stoichiometry of fuel could have marked effects on the irradiation behavior of fuel and on cladding/fue 1 compatibility." 


\section{$X X . \quad$ COMPATIBILITY}

A. RECENT ITEMS OF INTEREST:

1) More attention should be given to possible fission product to cladding interactions. (48)

2) Evidence was obtained that interaction between mixed oxide fuel and sodium can occur. (14)

3) Structural instabilities in the presence of sodium with high carbon are more predominant in 304 than in 316 SS.

4) Corrosion studies on PFR pins indicate that the rate of loss is sensitive to oxygen content and broadly insensitive to velocity at velocities above $10 \mathrm{ft} / \mathrm{sec}$. (4)

B. PROBLEMS REQUIRING FURTHER STUDY:

1) Need exists to establish whether accelerated attack of the stainless steel cladding is due to vaporization of the fuel. (49)

2) More attention should be given to possible fission product to cladding interactions. (48)

3) Need exists to follow the UK, PFR studies. See excerpts and/or comments from Reference 4 below:

"PFR studies indicate that no direct compatibility problems between stainless steel and nickel base cladding with oxide fuels at temperatures of interest (up to $700{ }^{\circ} \mathrm{C}$ ) are known, although indirect problems associated with fission products may occur. No specific PFR program has been mounted on compatibility between mixed oxide fuel and cladding. The results obtained from pins irradiated to $700{ }^{\circ} \mathrm{C}$ do not indicate a general problem, although instances of cladding attack have been noted." 
4) Need exists to study compatibility. Density has a deleterious effect on compatibility. However, GE-APD finds no dependence of chemical attack on density.

5) Need exists to follow the GE, FCR studies. See excerpts and/or comments from Reference 14 below:

"FCR studies indicate that it is of importance to determine if the ingress of coolant into the hot fuel matrix could cause high pressure transients, due to coolant vaporization, and result in fuel column deformation and cladding strain or rupture. It is also important to evaluate the long-term chemical compatibility of coolant and fuel should the reaction product, if any, have significantly lower conductivity or density properties than the original fuel."

6) Need exists to study the effect of sodium monoxide. See excerpts and/or comments from Reference 14 below:

"An analysis of the free energies of formation of FCR fuel and coolant indicate that the materials are chemically compatible in so far as bulk changes in chemical state are not thermodynamically predicted. However, the presence of sodium monoxide may alter the fuel properties significantly."

7) Need exists to study the fuel-coolant interaction. See excerpts and/or comments from Reference 14 below: "Examination of the FCR short-term 'logging' specimens revealed that the urania specimens were unaffected by the sodium, while the mixedoxide specimens showed evidence of incipient interaction with sodium, particularly in the cooler peripheral regions of the fuel. More 
recent examinations of unintentionally defected mixed-oxide specimens, which operated up to $500 \mathrm{~h}$ in sodium or Nak, show evidence of fuel-coolant interaction."

8) Need exists to follow UK compatibility studies. See excerpts and/or comments from Reference 7 below: "The possibility of PFR fuel interaction with flowing sodium exists if can failure occurs. PFR experiments with stoichiometric uranium dioxide resulted in very minor uranium losses to coolant, and again agree with observations of defected irradiated stoichiometric mixed oxides."

9) Need exists to study clad-coolant compatibility and acceleration of transformations due to stress. See excerpts and/or comments from Reference 30 below:

"Structural instabilities in the presence of high carbon are more predominant in 304 than in the 316 material. Further difficulties are noted in that it continues to suffer these transformations after the carbon source has been removed through redistribution of the carbon and undergo acceleration of these transformations (transformation of the $\mathrm{M}_{23} \mathrm{C}_{6}$ carbides to $\mathrm{M}_{7} \mathrm{C}_{3}$ occurs along with the formation of ferrite) due to stress. Stress appears to have a threshold level. The threshold is timetemperature-carbon controlled."

10) Need exists to further develop a corrosion model. See excerpts and/or comments from Reference 50 below:

"A corrosion model for predicting weight losses as a function of liquid-metal 
velocity and downstream distance was correlated for stainless steel corrosion rates in sodium at $1200^{\circ} \mathrm{F}$. Actual metal loss rates are predicted to be higher than those measured experimentally due to the compensating effect of weight gains." 


\section{COOLANT FLOW CHARACTERISTICS}

\section{A. RECENT ITEMS OF INTEREST:}

1) Detailed PFR studies have shown that very severe local coolant blockage can occur with only a small indication on mixed mean outlet temperature from a subassembly. This is potentially one of the most serious types of deterioration that may occur, firstly because of the difficulty of detection, and secondly because of the difficulty of predicting the course and timescale of the sequel. (4)

2) The rod bundle is the only commercial BWR fuel configuration, yet there are very few experimental data available on its hydrodynamic stability.

B. PROBLEMS REQUIRING FURTHER STUDY:

1) There is a need to study flow mixing. See excerpts and/or comments from Reference 52 below:

"The EBR-II subassembly has more flow area for its external fuel elements than for its internal elements, so the former receive more coolant flow than the latter as verified by local velocity measurements. Without mixing, the average coolant temperature rise associated with the external elements is $60 \%$ of that associated with the adjacent interior elements. However, thermal calculations show that with mixing, the external element rise increases $17 \%$ and the adjacent element rise decreases $22 \%$. Mixing does not significantly lower the temperature rise associated with the elements two rows away from the external elements."

2) Need exists to establish rod bundle flow characteristics. See excerpts and/or comments from Reference 51 below:

"The rod bundle is the only commercial boiling-water reactor-fuel configuration, yet 
there are very few experimental data available on its hydrodynamic stability. Hydrodynamic stability studies indicated that a rod bundle did not exhibit a well-defined threshold of instability. The dynamic behavior of the rod bundle was dominated by flow-void feedback. To determine the threshold of instability of the rod bundle, autocorrelation analysis had to be employed. The greater freedom of movement offered to voids by the rod bundle's geometry may be the cause of its diffuse threshold of instability."

3) Need exists to study coolant blockage in subassemblies. See excerpts and/or comments from Reference 4 below:

"Detailed PFR studies have shown that very severe local coolant blockage can occur with only a small indication on mixed mean outlet temperature from a subassembly. This is perhaps potentially one of the most serious types of deterioration which may occur, firstly because of the difficulty of detection, and secondly because of the difficulty of predicting the course and timescale of the seque1."

4) Need exists to study transient boiling of sodium. See excerpts and/or comments from Reference 53 below:

"Calculations for a typical fast-breeder figuration having $\mathrm{UO}_{2}$ fue 1 rods and 50 vol\% sodium coolant led to the following general conclusions:

a) The rate of coolant expulsion from the channel exit is extremely rapid 
once boiling starts and is sensitive

to the coolant temperature profile in

the 1 iquid portion of the channel.

b) The inlet coolant flow decays rapidly

to zero, typically by the time $20 \%$

of the channel is boiling.

c) Pressure buildup in the channel is

not excessively large, typically

less than ten atmospheres." 


\section{FAILURE MECHANISMS}

\section{A. RECENT ITEMS OF INTEREST:}

Clad melting, rather than fuel vapor pressure, was established, by GE-APD as the ultimate failure mechanism in zero burnup material. (8)

\section{B. PROBLEMS REQUIRING FURTHER STUDY:}

1) Need exists to establish the ultimate failure mechanism for irradiated fuel.

2) Can mixed oxide fuel undergo more than one transient?

3) Need exists to study both transgranular and intergranular modes of failure in cladding.

$$
\text { (4) }
$$

4) Need to study possible modes of failure. See excerpts and/or comments from Reference 11 below:

"In selecting a fuel-clad combination for a reactor, two modes of failure must be considered. Either the fuel element will crack and release fission products or it may swell without cracking and block coolant passages. Prediction of failure processes remains difficult. For example, in one study of superheat fuel elements, the fission-product release rate from a naturally defected element could not be predicted from measurements made on deliberately defected elements. In another program, it is suspected that fuel swelling as defined in a thermal reactor is not comparable with the swelling which is expected in a fast reactor based upon the substantial difference in burnup between the fuel surface and center. Thus, 
even when experimental data are available, interpretation may prove difficult, if not impossible."

3) Need exists to study the factors involved in the selection and design of reactor materials. See excerpts and/or comments from Reference 11 below:

"Selection and design of reactor materials will be enhanced if the following points are considered:

a) The majority of tests used to evaluate reactor fuels and materials are comparative, not absolute. They will show how materials will compare with one another, but will not permit prediction of service performance.

b) Out-of-reactor testing will not necessarily indicate how materials will behave in-reactor. In-reactor testing must be interpreted with caution.

c) In materials selection and development for a specific reactor system, the limiting mode of failure must be defined. The designer must specify what constitutes failure, show what materials-design data are needed to permit prediction of onset of failure, and if possible, see that this is verified experimentally.

d) Finally, the use of statistics to define failure must not be attempted unless it is clearly shown that specified failures are permitted and that the system can compensate for them."

6) It is necessary to experimentally determine the point of fuel rupture, not only on new fuel but on fuel at various burnups up to the maximum anticipated in the reactor. 
7) Need exists to experimentally verify the damage factor. See excerpts and/or comments from Reference 8 below: "GE-APD studies indicate that it is necessary to define the small local damage factor (the point of incipient damage) where one begins to deform the cladding. The factor needs to be defined in terms of fuel temperatures. The factor can be described analytically but must be experimentally verified."

8) Need exists to establish the failure limit. See excerpts and/or comments from Reference 8 below:

"According to GE-APD, the time to reach the assumed failure limit (the temperature range of interest being from the melting point up to about $6500^{\circ} \mathrm{F}$ - this is where one might expect failure, depending on the burnup of the fue 1 ) is approaching one second. This relatively long time is due to two things: the strong Doppler and the low conductivity of the fuel. This relatively slow temperature rise enables one to make an adequate experimental simulation using the TREAT Reactor."

9) Need exists to determine allowable number of transients in FFTF. See excerpts and/or comments from Reference 8 below: "GE-APD believes that the first transient (at least to the melting point, and a little above) actually does not cause the problem. It is the second transient that causes the problem and they have observed this in SEFOR tests. The fuel densified locally after the first transient and after the second transient, there simply is not enough room for differential radial expansion. GE-APD emphasizes 
that in a power reactor, and hopefully in FTR, one would have only one transient. One would hope to avoid a second transient (or at least replace the fuel)."

10) Need exists to establish answers to these questions: (74
a) What program is needed to demonstrate that the porosity will stay where you want it?
b) What is necessary to prove to ACRS, for example, that you have a safe system.

11) Need exists to establish fuel design limit. See excerpts and/or comments from Reference 8 below:

"GE-APD has, for the present, selected fuel design limits that preclude axial fuel movement due to melting; that is to say, all fuel is kept below incipient melting in the steady state, and no fuel rises above the liquidus during an overpower transient." 


\section{OPERATION OF FAILED FUEL}

\section{A. RECENT ITEMS OF INTEREST:}

No Entries.

B. PROBLEMS REQUIRING FURTHER STUDY:

1) Behavior of defected fuel pins needs to be studied. (54)

2) The effect of water on fuel behavior needs to be studied. See excerpts and/or comments from Reference 18 below:

"PRTR tests show behavioral differences between nondefected and defected mixed oxide fuel rods. It is felt that the proposed rupture mechanism is not unique with vibrationally compacted $\mathrm{UO}_{2}-\mathrm{PuO}_{2}$ fuels and that a similar occurrence could take place with pellet-containing fuel." 


\section{EXAMINATION EQUIPMENT}

\section{A. RECENT ITEMS OF INTEREST:}

No Entries.

B. PROBLEMS REQUIRING FURTHER STUDY:

1) There is a need to study the use of a profilometer. GE-APD thinks the profilometer is the most valuable tool known for establishing the effect of mechanical fuel-cladding interaction.

2) The possibility of a neutron television system for fuel inspection needs to be explored. See excerpts and/or comments from Reference 25 below:

"A neutron television system can be used in $10,000 \mathrm{R} / \mathrm{hr}$ fields for complete inspections of relatively high radio-activity fuel capsules and can provide immediate inspection information as to the alignment and placement of all internal components. The shape and dimensions of the fuel can be determined as well as deformations of jacket material. The location of thermocouples, spacer plates, and other objects in the capsule can be determined. Externally imposed vibration on the capsule permits a means of observing if any of the components are loose or misplaced." 


\section{TRANSIENT CONDITIONS}

\section{A. RECENT ITEMS OF INTEREST:}

1) The first transient (at least to the melting point, and a little above) doesn't cause the problem; it is the second transient which causes fuel pin failure (observed in SEFOR tests).

2) TREAT tests with vibrationally compacted $\mathrm{UO}_{2}$ indicate that simulated high burnup fuel fails by clad rupture and simulated low burnup fuel fails by the mechanism of clad melting. (55)

3) Transient performance of FCR fuel pins indicates a considerable margin between demonstrated performance limit ( $1 \%$ cladding deformation) and postulated credible accidents. (56)

4) TREAT tests with high burnup (70,000 MWd/tonne) mixed oxide pin by GE-APD indicate that the release of fission gas from irradiated fuel (during a transient that goes to a substantial fraction of fuel melting) constitutes a primary contribution to the failure mechanism for the fuel. (56)

5) TREAT tests show that both the peak pressures in the autoclave and the maximum rate of pressure rise were higher for packed powder fuel than for pellet fuel.

B. PROBLEMS REQUIRING FURTHER STUDY:

1) Need exists to study the possibility of subsequent reassembly of fuel, since during an accidental excursion the fuel tends to separate axially. (22)

2) Need exists to evaluate the empirical indications that there is a large release of fission gas during transients.

3) Need exists for more studies on effect of burnup on mixed 
oxide fuel in packed powder and pellet form. See excerpts and/or comments from Reference 55 below:

"Tests with $\mathrm{UO}_{2}$ in TREAT indicate more energetic pressure pulses with packed powder than with pellet fuel. The tests also indicated that simulated high burnup specimens fail by clad rupture while simulated low burnup samples fail by the mechanism of clad melting."

4) Effects on fuel-cladding transient performance of fission product formation, fission gas release, and central void formation resulting from short-and long-term, steady-state irradiations need to be established. Some are currently under investigation. (57)

5) More transient behavior stüdies with high burnup fuel are needed. There has been only limited success to date on this problem.

6) Need exists to study effect of transients on fission products. Examination of irradiated fuel has shown that fue 1 melting during a transient resulted in agglomeration of the metallic fission products into a single mass of extremely radioactive material.

7) Need exists to study problems involved in conducting mixed oxide meltdown tests in the transient reactor test facility. Uranium pin experiments have progressed to the point of meltdown tests on fuel contained in sodium loops sized for 7 -pin clusters. (58)

8) Need exists to evaluate the suggested approach (employ highly enriched samples but with representative plutonium content) on mixed oxide cluster meltdown tests. (58)

9) Need exists to study whether limit (time at $\sim 200 \mathrm{~W} / \mathrm{g}$ limited to about $20 \mathrm{sec}$ ) on TREAT tests allows sufficient testing to be done. (58) 
10) Need exists to continue the TREAT tests with irradiated FFTF mixed oxide fuel to determine the margin between the demonstrated performance limit and postulated credible accidents. See excerpts and/or comments from Reference 56 below:

"GE-APD tests indicate considerable margin

exists with FCR pins. The release of fission gases from any fuel during trans-melting transients is a driving force for potential fuel relocation and dispersion which should be included in future accident analyses."

11) Need exists to further evaluate use of TREAT for study of overpower and flow-decay incidents. (58)

12) Need exists to conduct additional studies on meltdown behavior of sodium-cooled, mixed-oxide, fast reactor fuel. One of the problems of importance in the evaluation of the safety of nuclear reactors (meltdown behavior of watercooled thermal reactor, $\mathrm{UO}_{2}$ fuel elements) has been simulated quite realistically in an experimental investigation in TREAT. (59)

13) Need exists to evaluate effects of different types of transients (e.g., power excursion and loss-of-coolant simulations). In some experiments, molten $\mathrm{UO}_{2}$ ran out of clad in latter but not in former tests. (59)

14) Need exists to study mixed oxide fuel pins in TREAT and obtain data on destructive fragmentation. See excerpts and/or comments from Reference 60 below:

"Irradiated $\mathrm{UO}_{2}$ pins have been tested and no evidence of destructive fragmentation noted. Also, the fuel tended to maintain shape without disintegrating, splitting, frothing, or undergoing significant changes from cylindrical geometry associated with the excursion." 


\section{SAFETY}

\section{A. RECENT ITEMS OF INTEREST:}

1) There is a deficiency in defining absolute materials limitations. (11)

2) A mass communication-media is needed so the entire nuclear industry is aware of the nuclear standards that are now, or will soon be, available.(61)

3) Three variables - smear density, allowable maximum fuel temperature, and required fuel life - become limiting when the fuel element design is considered.

4) UK data indicate that in annular pellet oxide pins up to $0.7 \mathrm{~mm}$ ID, the principal can-stressing mode will not derive from gas pressures in the plenum but from swelling in the fuel. (16)

5) GE-APD has, for the present, selected fuel design 1 imits that preclude axial fuel movement due to melting. That is, all fuel is kept below incipient melting in the steady state, and no fuel rises above the liquidus during an overpower transient. (8)

6) Accepted safety criterion for PFR fuel pins is that creep strain will be $\leq 0.1 \%$ over the life of the element. (36)

7) GE sees no evidence that annular fuel is unstable. (8)

8) PFR studies indicate that a satisfactory fuel fabrication route exists and that $5 \%$ burnup in stainless steel cladding at up to $650{ }^{\circ} \mathrm{C}$ can be achieved in a suitable design that provides for full gas release. (7)

9) It is necessary to define the small local damage factor (the point of incipient damage) where one begins to deform the cladding and it must be experimentally verified. (8) 
10) Release of fission gases from any fuel during trans-melting transients is a driving force for potential fuel location and dispersion, and should be included in future accident analyses. (56)

11) Clad me1ting, rather than fuel vapor pressure, is the ultimate failure mechanism in zero burnup fuel. (8)

12) A ratchetting mechanism may be responsible for a multiple fracture in a packed powder PFR pin. (4)

13) Increasing the time (e.g., by having a large Doppler coefficient) before either boiling or burnout occurs is very important to GE-APD in the FCR studies. (8)

14) PFR fuel pins are sealed and have a plenum at the cool end for accommodation of fission gases. They were chosen to avoid the substantially unknown reactor circuit problems posed by vented fuel. (4)

B. PROBLEMS REQUIRING FURTHER STUDY:

1) Need exists to evaluate the possibility of ratchetting. The PFR pins have a central strut to prevent fuel movement in case of ratchetting. (16)

2) Was a ratchetting mechanism involved in the failure of a PFR vibrationally-compacted fue 1 pin? (4)

3) Need exists to study methods for defining temperature and pressure limits. See excerpts and/or comments from Reference 11 below:

"There is a potential for failure of a nuclear pressure vessel following neutron embrittlement, but there is no clearly acceptable method for defining limiting temperatures and pressures. Similarly, prediction of service fatigue failure based on laboratory tests is not possible." 
4) Need exists to study the ratchetting mechanism. See excerpts and/or comments from Reference 14 below:

"One specimen, cycled 100 times to a $\int_{\mathrm{Ts}}^{\mathrm{Tc}} \mathrm{kd} \theta$ value of $48 \mathrm{~W} / \mathrm{cm}$, was strained up to $0.008 \mathrm{in.} \mathrm{maximum} \mathrm{on} \mathrm{the}$ cladding diameter. This strain was possibly due to fuel-clad ratchetting rather than sodium vapor pressure."

5) Need exists to study Doppler coefficients in the region of fuel melting, since incipient melting has been set as the upper fuel limit under transient conditions.

6) Need exists to study the axial expansion effect. See excerpts and/or comments from Reference 62 below:

"The axial fuel expansion is important in SEFOR since this effect must be subtracted from the total fuel reactivity in order to obtain the Doppler effect. Segmented fuel is used in SEFOR to reduce the axial expansion effect."

7) Safety requirements need to be studied since there is no experience with an FTR type of core.

8) Need exists to study reactivity biases. See excerpts and/or comments from Reference 63 below:

"Standard PWR nuclear-design procedures have been found to yield good estimates of initial reactivity and control-rod worths in this plutonium-fueled design (the $\mathrm{PuO}_{2}-\mathrm{UO}_{2}$ involved in the Saxton Plutonium Program contained 6.6 wt $\mathrm{PuO}_{2}$ ) for which mockup criticals were available. The existence of reactivity biases would indicate that further experimental and analytical efforts in the plutonium area are desirable."

9) Need exists to evaluate fuel homogeneity. See excerpts and/or comments from Reference 3 below:

"A safety consideration which concerns ceramic fuels in fast reactors pertains to the 
degree of inhomogeneity that is acceptable in the fuel. Coprecipitated material or solid solutions are most desirable for assuring that the full value of the prompt Doppler effect is available. However, improved fabrication and nondestructive examination techniques are being developed which may permit the use of physical blending techniques to produce mixtures of uranium and plutonium that are homogeneous to the scale of a few microns."

10) A presently unresolved potential safety program is associated with sodium-bonded ceramic fuels that may release significant amounts of fission gas during irradiation. See excerpts and/or comments from Reference 3 below:

"Gas released into the sodium bond might possibly form fixed bubbles of sufficient size to limit heat transfer through the liquid metal bond. Also, a leak in the lower part of the cladding after the fuel element has become pressurized by fission gas release could result in complete loss of sodium bonding between the fuel and cladding. In both cases local overheating of the fuel and cladding would occur with potentially serious consequences. The design implications of the problem are evident. If, for safety, it is necessary to design a sodium-bonded ceramic fuel element with a low heat rating so that loss of liquid metal bond can be tolerated without cladding failure, a strong incentive exists to specify a gas-bonded element from the start." 
11) Need exists to reduce the uncertainty in the Doppler coefficient. See excerpts and/or comments from Reference 64 below:

"Estimates of the uncertainty in the calculation of the Doppler coefficient range from $20 \%$ to a factor of 2 . The sodium temperature is also uncertain since it is due to the complex interaction of a number of variables."

12) Need exists to study minor accidents which could force rods out of the reactor core, and due to the reactivity addition, cause a more serious accident. See excerpts and/or comments from Reference 65 below:

"FARET studies used these mechanisms:

a) pressurization by blanket gas system or by coolant pumps

b) coolant hydraulic hammer or spray

c) pressure of expanded coolant vapor

d) load from ruptured hydraulic hammer barriers.

Slow excursions produced peak core sodiumvapor pressures which were inadequate to part the fuel subassemblies. Fast (shorter period) excursions than those with a $0.04-\mathrm{sec}$ period produce peak core pressure potentially large enough to part the subassemblies."

13) Need exists to study evidence of ratcheting. Ratcheting was encountered once in extremely fast transient tests conducted as part of the safety program at Idaho. (66)

14) Need exists to determine the fuel design limit. As mentioned above, three variables - smear density, allowable maximum fuel temperature, and required fuel life - become limiting when the fuel element design is considered. 
15) Need exists to study credible FFTF accidents. Current analyses of credible FCR accidents show that the percentage of fuel that becomes molten in an accidental excursion does not exceed that volume of the fuel that has released all of the gases generated in it during steady-state operation. (22) 


\section{DESIGN CRITERIA}

\section{A. RECENT ITEMS OF INTEREST:}

Accepted safety criterion for PFR fuel pins is that creep strain will be $\leq 0.1 \%$ over the life of the element. (36)

B. PROBLEMS REQUIRING FURTHER STUDY:

1) Need exists to closely follow UK work on pin design criteria. See excerpts and/or comments from Reference 4 below:

"The major phenomena which need to be taken into account in designing the pin are fission gas pressure, fuel swelling, thermal stressing due to internal heating and coolant temperature inhomogeneities, and loss of cladding due to corrosion. The PFR studies show that over the majority of the pin dwell time, the strain is very small and then it builds up very rapidly."

2) Need exists to follow the UK work on pin criterion. See excerpts and/or comments from Reference 4 below:

"The PFR pin was originally designed with the priviso that the creep strain should be limited to $0.1 \%$. It is now believed that this value could be amended upwards somewhat, but in view of the creep law, the permissible dwell time would not be very largely affected. It is perhaps worth noting that this criterion is important in the sense that pins will inevitably fail due to internal pressure if they are left in the reactor long enough and prior failure due to some other mechanism does not occur." 
3) Need exists to study thermal stresses. See excerpts and/or comments from Reference 4 below:

"Two consequences of thermal stress are considered relevant. Firstly, power changes could lead to plastic fatigue of the outer tubing fibres of the Coffin type. Secondly, if thermal stress is superposed on internal pressure, incremental increases in clad diameter could occur on power cycling; this has been called 'progressive ratchetting!."

4) Need exists to establish an adequate swelling theory. See excerpts and/or comments from Reference 4 below:

"At present, no adequate theory to take account of swelling is known. Theories making assumptions about the creep and yield properties of ceramic fuel under fuel under irradiation can be set up, but shortage of the physical properties data preclude the establishment of working design rules at present. The PFR design has been formulated on the basis that local voidage must be available to accommodate solid fission product swelling. This leads to a fuel density specification of about $80 \%$."

5) Need exists to study subassembly design criteria. See excerpts and/or comments from Reference 4 below:

"The two main criteria which have conditioned PFR subassembly design are firstly, that the restraint of grids shall prevent unacceptable pin bowing from occurring, and secondly that the wrapper shall be strong enough to withstand differential pressure arising from the progressive pressure drop on the inside and (effectively) stagnant coolant on the outside, i.e., a uniform external pressure." 
6) Need exists to study pin bowing. See excerpts and/or comments from Reference 4 below:

"Assemblies of highly rated pins have a strong. tendency to thermal bowing instability, since any pin deflection tends to produce a temperature distribution leading to further deflection in the same direction.

"Bowing of pins imposes stresses in the pins which must be analyzed as a function of distance from the free or fixed end of the pin. These stresses must be taken into account as another possible source of ratcheting straining, since in severe cases, plastic hinges may form at grids."

7) Need exists to study potential performance problems. See excerpts and/or comments from Reference 4 below:

"The ratio of plenum to fuel volumes is designed in PFR fuel pins to limit the internal pressure to a value at which the creep strain in the can will be small. 'Small' in this context means within the likely ductility of the irradiated cladding, and of such a magnitude that significant loss of coolant flow will not occur.

"Two effects could undermine the design:

a) Firstly, the pin is designed on out-pile creep data which indicate that primary creep is negligible and that secondary creep will describe the full life of pins. A pronounced irradiation degradation of creep strength would nullify the design basis. Calculations show this effect not dominant. 
b) The second effect is blockage

of the plenum by condensible

fission products. This would

be very serious indeed, leading

to a rapid build-up of internal

pressure and clad rupture.

Examination of pins at approxi-

mately 5\% burn-up gives promise

that this latter effect will not

be insuperable."

8) Need exists to study differential expansion in the fuel subassembly. The PFR design currently employs grids which take note of the fact that axial differential expansion between the pins and the wrapper (to which the grids are effectively attached) could be accommodated by purely elastic deflection of the grids, together with minor slipping increments between pins and grids. (4)

9) Need exists for extensive studies to be conducted on subassembly design aspects. See excerpts and/or comments

from Reference 4 below:

"UK workers indicate that flow information is required for two design aspects of subassemblies, namely, pressure drop and flow distribution and mixing.

a) "Pressure Drop: The pin fractional

loss is a function of the axial spacing between grids. With a pin bundle with effectively no grid support, the hydraulic diameter concept, using conventional pipe friction losses, is accurate to about $15 \%$. With support grids offering $27 \%$ blockage to flow area 
relevant to DFR experimental subassemb1ies), and spaced apart by 12 equivalent hydraulic diameters, the frictional loss alone can increase by up to $16 \%$ : the tota 1 loss with the grids and pins together is increased by about $70 \%$. "The losses calculated for PFR grids using conventional expansion, contraction, and friction coefficients have also been compared with experiment and sliown to be some $25 \%$ too low.

"Measurements across a complete fullsize PFR subassembly have shown that the pressure drop can be some $10 \%$ higher than that obtained on ideal large-scale models. This is attributed mainly to the effect of departures of the detail of the full-scale prototype from the models.

b) "Flow Distribution and Mixing: Measurements have been compared with theoretical estimates, and so far it has not been possible to obtain agreement better than about $20 \%$. The ratio of the center-to-edge channel flows, for example, has been shown to be very dependent on the detailed grid geometry. Al1 design changes, other than minor changes, are therefore still tested experimental1y.

"Variations in the cross-section of the grid strips from that of a simple 
rectangle have led to increases in mixing by a factor 10 , at the expense of some pressure drop.

c) "Endurance Testing: The submission of subassemblies to sodium at reactor temperature and flow, and to thermal shocks representative of power changing, has been regarded as a necessary part of the out-of-pile endorsement of designs. Thus, while in an early test inadequate standards of pin manufacture were shown up, in a more recent test in which a DFR experimental subassembly was submitted to 1000 hr steady running in $\mathrm{NaK}$ at $600{ }^{\circ} \mathrm{C}$ and 20 thermal shocks between $600{ }^{\circ} \mathrm{C}$ and $200{ }^{\circ} \mathrm{C}$, nothing untoward was revealed, giving confidence that the design is adequate for reactor loading.

d) "Pin-Grid Interactions: One detailed aspect of subassembly design which has received consideration is the interaction between pins and grids resulting from relative movement due to differential thermal expansion. This problem has become more significant as the strength of grids has been reduced, resulting from design changes aimed at reducing pressure losses. It has proved possible to design a grid that is sufficiently elastic to move with the pins over 
the major portion of its area, yet sufficiently strong to withstand coolant forces. Reasonable agreement has been achieved between theory and experiment in this design." 


\section{XXVIII . REPROCESSING}

A. RECENT ITEMS OF INTEREST:

PFR reprocessing studies show that dissolution rates of mixed oxide fuel were enhanced as a result of irradiation.

\section{B. PROBLEMS REQUIRING FURTHER STUDY:}

1) Need exists to conduct reprocessing studies. See excerpts and/or comments from Reference 7 below:

"PFR studies show dissolution rates were enhanced as a result of irradiation. The sludge consisted principally of the fission products ruthenium, molybdenum, rhodium and technetium, the latter mainly in elemental form. These findings agree largely with those reported by Goode at ORNL on work carried out on the coprecipitated mixed oxide pins irradiated by General Electric in their studies on fast reactor ceramic oxide fuel."

"The insoluble fission products form about $0.5 \%$ of the core weight, somewhat less than the figure of $2 \%$ residues found at ORNL. Results confirm Goode's conclusion that feed clarification will be necessary before solvent extraction purification."

2) Need exists to conduct recycling studies. See excerpts and/or comments from Reference 7 below:

"Work has been undertaken by the UK on problems arising in the recycling of high burn-up fuels to give highly decontaminated products suitable for refabrication behind light shielding. The fuel cycle for the PFR is based upon fuel recycling by a solvent extraction purification 
route to yield a final product of $\beta-\gamma$ activity

equivalent to a few mc-MeV per kilogram of total metal, utilizing an existing separation plant. This fact, has influenced to some extent, the selection of the route for fue 1 material preparation."

3) Need exists to study chemical attack on fuel pellets. As far as chemical attack goes, GE-APD finds no difference with pellets (in sodium) as a function of density.

4) Need exists to study effect of fission products on oxidation. In recent ANL recovery studies, lower oxidation rates were noted with $\mathrm{UO}_{2}-\mathrm{PuO}_{2}$ fission product pellets than with pure $\mathrm{UO}_{2}$ pellets. $(67)$ 
XXIX. VENTED FUEL

A. RECENT ITEMS OF INTEREST:

1) PFR fuel pins are sealed and have a plenum at the cool end for accommodation of fission gases. They were chosen to avoid the substantially unknown reactor circuit problems posed by vented fuel. (4)

2) The threshold for incipient damage may be increased appreciably with the use of properly vented fuel. (8)

B. PROBLEMS REQUIRING FURTHER STUDY:

1) Need exists to evaluate vented fuel. Sealed pins, with a plenum at the cool end for accommodation of fission gases, were chosen for PFR to avoid the substantially unknown reactor circuit problems posed by vented fue1. (4)

2) Need exists to study vented fue1. See excerpts and/or comments from Reference 8 below:

a) "The obvious advantage of vented fuel (lower hoop stress in cladding) is not necessarily the most important according to GE-APD. An important point is that one may have a cleaner reactor system with vented fuel than without vented fuel."

b) "There is a good chance that for a given burnup level there will be fewer gross failures with vented fuel than with nonvented fuel. Vented fuel avoids a sudden release of fission gas, with possible gas blanketing of adjacent pins."

c) "By using vented fuel, one may reduce the amount of fuel that would fail if you should have a small accidental transient."

d) "With properly vented fuel, the threshold of incipient damage may be increased appreciably." 
XXX. ANALYTICAL MODELS

\section{A. RECENT ITEMS OF INTEREST:}

No Entries.

B. PROBLEMS REQUIRING FURTHER STUDY:

1) Need exists to improve calculational models. See excerpts and/or comments from Reference 68 below:

"Although certain effects such as fuel cracking and pore migration are not included in one analysis (using CYGRO), and data on other effects such as fission-induced creep are as yet incomplete, the dimensional predictions fall mostly within the range of experimental scatter. The prospects of this approach are therefore encouraging."

2) Need exists to improve knowledge of input data. See excerpts and/or comments from Reference 69 below:

"The weaknesses of the KER-4 computer program are largely those of poor knowledge of input functions. Gap conductance variation, although extensively studied, is still poorly understood. Behavior of thermal conductivity of oxide fuels both as a function of porosity and fission depletion of the fuel is only established for $\mathrm{UO}_{2}$ at low fission depletions."

3) Need exists to improve computer codes. See excerpts and/or comments from Reference 70 below:

"The advantage of one code (NUKER), even in its elementary form, is its usefulness in conducting rapid design parameter studies. These include relative comparisons of proposed designs and assessment of the sensitivity of performance indexes like clad burden or peak central temperature on individual mechanical of thermal properties." 
4) Need exists to develop analog and digital computer codes. See excerpts and/or comments from Reference 71 below:

"The analog computer model was helpful in one experiment in understanding the advantages of running a relaxation test, rather than one in which the load is held constant. In carrying out this test, the digital computer was an indispensable tool without which the labor of analytical computation would have offered almost insurmountable difficulties." 
XXXI. FUTURE DESIGN AND EXTRAPOLATION BEYOND EXISTING DATA

\section{A. RECENT ITEMS OF INTEREST:}

1) PFR data indicate that the fuel pins are capable of reaching mean burnups in excess of $5 \%$, under PFR irradiation conditions. (4)

2) Above $7 \%$ mean burnup, fuel swelling caused pin diameters to increase, and this now appears to be the most serious problem to be overcome before $10 \%$ burnup can be reached satisfactorily. (4)

3) The indications are that fuel swelling is the immediate obstacle to reaching $10 \%$ burnup. (7)

4) In flowsheeting the PFR fuel preparation plant, the UK workers have taken into account the possibility of replacing mixed oxide (current fuel) by carbide. (7)

5) While high burnup is the target for all fast reactor fuel element designs, it is the optimum fuel cycle cost that is the real FBR target, and the many parameters involved require detailed study. (7)

6) The stretch capabilities of mixed oxide fuel, according to GE-APD, seem to be in the same category as those being explored for conventional oxide fuels and this mainly entails running the fuel in the molten condition. (8)

7) GE-APD has run mixed oxide fuel as high as $45 \mathrm{~kW} / \mathrm{ft}$. However, they are not sure there is as yet any reasonable design basis for operating routinely at this rod power. (8)

8) First goal of the PFR program is to reach burnup of $5 \%$ (average) of heavy atoms at a hotspot temperature of $600{ }^{\circ} \mathrm{C} .(4)$

9) Second PFR target is to extend the fuel performance to $10 \%$ (maximum) burnup at a hotspot temperature of $650{ }^{\circ} \mathrm{C}$. (4) 
BNWL -645

10) It must be expected that in annular pellet oxide pins up to approximately $7 \mathrm{~mm}$ OD, the principal can stressing mode will derive not from gas pressures in the plenum but from swelling of the fuel. (16)

11) Nothing has emerged on the PFR program to date to give any cause for concern either in the normal or defect behavior of fuel elements. (7)

12) The UK uses coprecipitated mixed oxide in PFR fuel pins. See excerpts and/or comments from Reference 7 below:

"This does not mean that a future choice would not involve physical mixing of urania and plutonia since considerable experience is being built up on the preparation of single phases bodies and on the irradiation of duplex fuels, such as those prepared by the U Nupak route." (Pneumatic Impaction route)

13) It is satisfactory to note that conventional materials of construction will be satisfactory for fuel reprocessing plants with this type of fuel (mixed oxide), since excellent uranium and plutonium recovery can be made at the dissolution stage without fluoride catalysed dissolution. (7)

14) The results of the development work on parts of the PFR oxide fuel cycle indicated that a satisfactory fuel fabrication route exists and that $5 \%$ burnup in stainless steel cans at up to $650^{\circ} \mathrm{C}$ can be achieved in a suitable design, which provides for full gas release. (7)

B. PROBLEMS REQUIRING FURTHER STUDY:

1) There is no serious doubt that $10 \%$ burnup can be reached, but it is a matter for detailed economic study to decide the optimum burnup to aim for, having regard to the design parameters that must be used to achieve a given burnup. 
2) Need exists to study carbide fuels. See excerpts and/or comments from Reference 7 below:

"The present UK view is that as a simple replacement for mixed oxide, enough is known about carbide to doubt its viability with the Reference design in the UK program. If it is found possible effectively to exploit its advantages of gas retention and/or high thermal conductivity, it opens design possibilities which may correspond to cheaper or more durable elements than are possible with oxide. Two obvious avenues are larger diameter pins and thinner cladding."

3) Need exists to continue cladding studies. See excerpts and/or comments from Reference 7 below:

"It is not clear at the moment what is the best balance between strength and ductility in cladding. More fuel element data are required. Molybdenum has been included in a minor way in the UK cladding program as representing a material with potential for a very high temperature operation, which could offset its nuclear drawbacks."

4) Need exists to continue studies on cladding and fuel strengths. See excerpts and/or comments from Reference 7 below:

"The major problems of gas release and fuel swelling will presumably be influenced by effective changes to cladding and fuel strength. These can be effected by thickness/diameter ratio changes in the clad, variations of cladding material and heat treatment, and fuel density changes."

5) Vented fuel studies need to be continued. See excerpts and/or comments from Reference 7 below:

"The role of vented fuel is not immediately clear if fuel swelling is the major bar to high burnup. 
Clearly it removes the problem of creep of the can under internal fission gas pressure. Vented fuel is included in the UK program in the expectation that the trend will be to more advanced steam conditions and, therefore, to higher can temperatures, when creep failures will assume major importance."

6) Need exists to establish fuel design for future use. See and/or comments from Reference 4 below:

"It has been established elsewhere that an economic fast reactor must employ fuel rated at approximately $200 \mathrm{~W} / \mathrm{g}$ (fuel) and taken to between $5 \%$ and $10 \%$ average burnup of heavy atoms. UK workers indicate that the design framework (it is assumed that a maximum $\int k d \theta$ value of $40 \mathrm{~W} / \mathrm{cm}$ or so is involved) within which a successful design must be sought involves the following facts:

a) Fuel

i) "In mixed oxide, gas release of about $90 \%$ will occur in vibrationally-compacted fuel and could be about $50 \%$ in pellet fuel. Approximately $25 \mathrm{ccs}$ (NTP) of fission gas per cc of fuel could be released in $10 \%$ burnup.

ii) "Fuel swelling of approximately 2 vol\% per at. $\%$ burnup will occur in both oxide and carbide fuel.

iii) "Condensible fission products corresponding to $3.4 \mathrm{cms}$ of pin will be formed by $100 \mathrm{cms}$ of $80 \%$ dense mixed oxide fuel in 10 at. \% burnup. 
b) Cladding

(The remarks below apply broadly to stainless steel and nickel base cladding).

i) "Irradiation substantially increases the yield stress of solution treated stainless steel below $650{ }^{\circ} \mathrm{C}$ and reduces its tensile ductility. Above $650{ }^{\circ} \mathrm{C}$ the yield stress may be lowered and the tensile ductility will be increasingly degraded with increasing temperature.

ii) "In cold worked stainless steel, the effect of irradiation is to lower ductility and increase yield strength below $650{ }^{\circ} \mathrm{C}$; above $650{ }^{\circ} \mathrm{C}$ the yield strength is not much altered but ductility is increasingly reduced with increasing temperature.

iii) "In solution treated and aged precipitation hardened nickel base alloys, there is a loss of tensile ductility at all temperatures. At $700{ }^{\circ} \mathrm{C}$ and above, the ductility may be very sma11."

iv) "From all the data available, it would be consistent to find cladding failures at not much more than $1 \%$ strain in pins."

7) Need exists to establish future FFTF fuel choices. See excerpts and/or comments from Reference 4 below:

"Ceramic fuel was chosen for PFR in place of metal on the grounds that the development problems were regarded as less difficult with the former; that very large thermal reactor development programs were studying ceramic fuel; and that more development potential in terms of varying reactor parameters appeared to be available to ceramic fuel. The same view is still taken, but the UK opinion is that the choice is not obvious, and that a metal-fuelled system is a viable target." 


\section{REFERENCES}

1. R. K. Anderson and J. T. Mommsen. "Status Report on BoilingWater Reactor Fuels," Trans. Am. Nucl. Soc., vol. 9(2), p. 538.1966 .

2. C. N. Spazaris. FFTF Functional Requirements, GEAP-5290. October 1966.

3. J. H. Kittel, E. L. Zebroski, A. Strasser, L. R. Kelman, W. E. Bailu, and J. H. Handwerk. "Plutonium Fuel Development for Fast Reactors in the U.S.", a paper at the Nuclear MetalIurgy Symposium held by the American Institute of Mining, Metallurgical and Petroleum Engineers, october 3-5, 1966, Lake Lawn Lodge, Delavan, Wisconsin.

4. J. F. W. Bishop, C. Boorman, G. O. Jackson, D. L. Linning, N. Parkinson, and A. E. Williams. Paper 4B/1, "Design and Development of Fuel and Fuel Elements for Prototype Fast Reactor", London Conference on Fast Breeder Reactors, May 17-19, 1966 .

5. J. H. Fiezd. An Engineering Review of the Fast Flux Test Facility (Phase I), GEAP-4470, pp. 4-55, 4-66, 4-68. May 1966 .

6. W. J. Bailey. Unpublished data. Pacific Northwest Laboratory, Richland, Washington. [Letter. Subject: Review of Draft Copy (dated July 16, 1965) of Supporting Information, Compized by $A E C^{\prime} s$ RDT Staff Members, for the LMFBR Fuels Evaluation Summary Report, dated January 18, 1966.]

7. N. Parkinson. Plutonium Fuels for Fast Reactors. United Kingdom Atomic Energy Authority, Dounreay Experimental Reactor Establishment, Thurso, Caithness, Scotiand, october 1966.

8. E. L. Zebroski, W. E. Baily, S. A. Rabin, and J. H. Fiezd. "Oxide Fuel, Status, and Stretch Capabilities", Fast Flux Test Facility Driver Fuel Meeting, BNWL-268. Pacific Northwest Laboratory, Richland, Washington. June 1966.

9. W. J. Baizey. Unpublished data. Pacific Northwest Laboratory, Richland, washington. February 1967. (BNWL-645RD, rough draft of this document plus working notes, is stored in FFTF Fizes.)

10. W. E. Roake. Unpublished data. Pacific Northwest Laboratory, Richland, Washington. [Letter. Subject: Comments on Visit by M. Robizzard, October 13, 1966; dated November 4, 1966.] 
11. William L. R. Rice (USAEC). "Materials Selection and

Design: A Key to Quality Assurance", Trans. Am. Nucl. Soc., vol. 9(2), pp. 407-408. 1966 .

12. L. G. Wisnyi, P. T. Lovejoy, G. J. Moyar, and J. E. Barnes, Jr. (KAPL). "In-Pile Mechanical Properties of Nuclear Euels", Trans. Am. Nucl. Soc., vol. 9(2), pp. 393-394. 1966.

13. J. Roth (NUMEC). "Anomalies observed in the Thermal Expansion of (Pu,U)O Solid Solutions by X-ray Diffractometry", Trans. Am. Nucl. Soc., vol. 9(2), p. 414. 1966.

14. F. W. Knight, W. A. Hendricksen, G. L. O'Neizl, and

W. L. Lyon (GE-San Jose). "Compatibility of Oxide Fuels

$\left[\mathrm{UO}_{2}+x\right.$ and $\left.(\mathrm{Pu}, \mathrm{U}) \mathrm{O}_{2}+x\right]$ with Sodium and NaK", Trans. Am. Nucl. Soc., vol.9(1), pp. 37-39. 1965.

15. S. A. Rabin, R. W. Darmitzel, and W. W. Kendalz (GE-San Jose). "Short-Term Fast-Flux (EBR-II) Irradiation of PuO -Uo, Fuel Pins", Trans. Am. Nucl. Soc., vol. 9(1), $p p \cdot{ }^{2} 41-42.1965$.

16. H. Lawton, K. Q. Bagley, E. Edmonds, and H. E. Tilbe. Paper 4B/4, "The Irradiation Behaviour of PlutoniumBearing Ceramic Fuel Pins", London Conference on Fast Breeder Reactors, May 17-19, 1966 .

17. J. Alzio, A. Biancheria, and W. E. Ray (WAPD). "Saxton Plutonium Project Materials Program", Trans. Am. Nucl. Soc., vol. 9(1), pp. 29-30. 1965 .

18. M. D. Freshley, R. G. Wheeler, J. M. Batch, and G. M. Hesson (BNW). "The Combined Failure of a Pressure Tube and Defected Fuel Rod in PRTR", Trans. Am. Nucl. Soc., vol. 9(2), pp. 398-399. 1966.

19. R. K. Andersen, and J. T. Mommsen. "Status Report on Boiling-Water Reactor Fuels", Trans. Am. Nucl. Soc., vol. $9(2), p$. 538. 1966.

20. J. B. Burnham, and L. G. Merker (BNW). "Cost of Fabricating Fuel Elements Containing High-Exposure Plutonium", Trans. Am. Nucl. Soc., vol. 9(1), pp. 296-297. 1965.

21. C. J. Kubit, D. R. McClintock, and H. M. Ferrari. "The Behavior of Water Vapor in $\mathrm{UO}_{2}$ During Irradiation", Trans. Am. Nucl. Soc., vol. 8(2), pp. 429-430. 1965. 
22. J. E. Hanson. "Response of Low-Burnup-Irradiated Mixed-Oxide (PuO $\left.\mathrm{O}_{2} \mathrm{UO}_{2}\right)$ Fuel to Transient Overpower", Trans. Am. Nucl. Soc., vol. 8(2), pp. 560-561. 1965.

23. J. D. Sease, R. B. Pratt, F. C. Davis, and A. L. Lotts. "Design of a Remote System for Fabrication of (Th-233U) ${ }_{2}$ Metal-Clad Fuel Elements", Trans. Am. Nucl. Soc., vol. g(2), p. 613. 1966 .

24. M. Zambernard, J. L. Brenan, and I. D. Thomas (NUMEC). "Preparation of $\mathrm{UO}_{2}-\mathrm{PuO}_{2}$ Fast-Reactor Test Specimens", Trans. Am. Nucl. Soc., vol. 9(2), p. 411. 1966.

25. H. Beraer and W. N. Beck. "Neutron Television Sustem Inspection of Radioactive Fuel Capsules", Trans. Am. Nucl. Soc., vol. 9(2), p. 597. 1966.

26. S. Y. Zamrik and L. W. Hu (Penn. St. U.). "Nuclear Irradiation Effects on the Dynamic Behavior of Pure Aluminum", Trans. Am. Nucl. Soc., vol. 9(2), pp. 429-430. 1966.

27. A. DePino. Jr. (BNW). "Helium Production by $(n, \alpha)$ Reactions in Stainless Steel", Trans. Am. Nucl. Soc., vol. 9(2), p. 386. 1966 .

28. W. R. Smazzey (WAPD). "Yankee Fuel Rods After Irradiation to 45,000 MWd/MTU", Trans. Am. Nucl. Soc., vol. 9(2), pp. 394395. 1966 .

29. D. D. Cannon, F. C. Davis, and J. D. Sease. "A Machine to Remotely Filz and Compact Nuclear Fuel Tubes by Vibration", Trans. Am. Nucl. Soc., vol. 9(2), p. 614. 1966.

30. R. H. Hiztz and R. C. Andrews (MSA Res.). "The Behavior of 304and 316-Type Stainless Steels in High Carbon Sodium", Trans. Am. Nucl. Soc., vol. 9(2), p. 426. 1966.

31. T. M. CampbezZ, D. W. Koch, and P. J. Kovach (B\&W-Ohio). "Model Sodium-Heated Steam-Generator Materials Studies", Trans. Am. Nucl. Soc., vol. 9(1), pp. 58-59. 1965.

32. B. H. Cherry, C. A. Besulieu, and A. H. Kazi (UNC). "Design of Helium-Bonded (U Pu)C Fuel-Pin Capsules for Fast-Flux Irradiations", Trans. Am. Nucl. Soc., vol. 9(2), pp. 418420. 1966 .

33. T. J. Pashos, H. E. Wilziamson, and R. N. Duncan. "Fuel Performance in Boiling Water Reactors", Trans. Am. Nucl. Soc., vol. 8(2), pp. 362-363. 1965. Also comments made during presentation of the paper at the meeting. 
34. M. D. Freshley, F. E. Painsko, and R. E. Skavdahl (BNW). "UO2-PuO2 High-Power-Density Fuel-Element Experience in PRTR", Trans. Am. Nucl. Soc., vol. 9(2), pp.397-398. 1966.

35. J. F. Gibbons and J. R. Dietrich. "Fuel Elements for Integral Superheat," Trans. Am. Nucl. Soc., vol. 9(2), pp. 538-539. 1966 .

36. L. Fisher, J. Pendleton, J. O. Pounder, and A. B. Washington. UK AEA, Dounreay). "Fuel Temperature Measurements in Mixed Oxide Elements", Nuclear Engineering, pp. 500-502. August 1966 .

37. W. E. Baizey, C. N. Craig, and E. L. Zebroski (GE-San Jose). "Effect of Diametral Gap Size on the In-Pile Performance of Fast Ceramic Reactor Mixed-oxide Fuel", Trans. Am. Nucl. Soc., vol. 9(1), p. 40.1965.

38. P. M. Magee and R. H. TromeZ. "Heat Transfer from Fuel Elements in a Tightly Packed, Liquid-Metal-Cooled Compact Reactor", Trans. Am. Nucl. Soc., vol. 9(2), pp. 569-570. 1966 .

39. M. D. Freshley, F. E. Panisko, and R. E. Skavdahz. Irradiation of $\mathrm{UO}_{2}-\mathrm{PuO}_{2} \mathrm{High-Power-Density} \mathrm{Fuel} \mathrm{Elements} \mathrm{in} \mathrm{PRTR",}$ Trans. Am. Nucl. Soc., vol.8(2), pp. 365-366. 1965.

40. W. L. Lyon and W. E. Baily. "The Melting Point of PlutoniaUrania Mixed-Oxide Fuels", Trans. Am. Nucl. Soc., vol. 8(2), p. 376.1965 .

41. M. F. Lyons, B. Weidenbaum, H. Hausner, and T. J. Pashos. "New Evidence to Delineate the UO 2 Molten Boundary", Trans. Am. Nucl. Soc., vol. 8(2), pp. 376-377. 1965.

42. A. S. Bain (AECL). "Postirradiation Structures in UO Quenched or Slowly Cooled from the Melt", Trans. Am. Nucl. Soc., vol. 9(1), pp. 27-28.1965.

43. R. C. Nelson and E. I. Zebroski (GE-San Jose). "IrradiationInduced Swelling Rates of $\mathrm{PuO}_{2}-\mathrm{UO}_{2}$ Fuels with Strong Radial Restraint", Trans. Am. Nucl. Soc., vol. 9(2) pp. 412-413. 1966 .

44. M. J. F. Notley, R. Destaies, and J. R. MacEwan. "The Fission-Product Gas Pressures in $\mathrm{UO}_{2}$ Fuel Elements During Irradiation", Trans. Am. Nucl. Soc., vol. 8(2), pp. 424425. 1965 . 
45. J. P. Bacca, M. J. Feldman (NAL-Idaho), and D. E. Mahagrin (CE). "EBR-II Driver-Fuel Surveizlance", Trans. Am. Nucl. Soc., vol. 9(2), pp. 417-418. 1966 .

46. W. J. Ross, K. H. Puechl, C. S. Caldwelz, J. Miles, F. Shipko, and W. C. Judd (NUMEC). "Post-Examination of $U_{2}-5$ wt\% PuO2 Fuels", Trans. Am. Nucl. Soc., vol. g(1), pp. 40-41. . 1965 .

47. R. W. Darmitzel, J. H. Davies, and R. E. Smith (GEValzecitos). "Alpha Autoradiography: A Technique for Examining Irradiated Fuel Material", Trans. Am. Nucl. Soe., vol. 9(1), pp. 64-65. 1965 .

48. J.H. Davies, R. F. Boyze, and J. F. Hanus. "Fission-Product and Heavy-Element Distributions in High-Performance UO 2 Fuels", Trans. Am. Nucl. Soc., vol. 8(2), pp. 378-379. 1965.

49. Ford Knight, S. A. Rabin, G. L. O'Neizz, and W. E. Baily. "High-Power Operation of $\mathrm{PuO}_{2}-\mathrm{UO}_{2}$ Fast Reactor Fuel", Trans. Am. Nucl. Soc., vol. 8(2), p. 345. 1965.

50. J. C. Mottley (WAPD). "A Corrosion Model for Correlating Simultaneous Weight Losses and Gains in Liquid-Metal systems", Trans. Am. Nucl. Soc., vol. 9(1), p. 59. 1965.

51. N. C. Pate. "Hydrodynamic stability of a Rod Bundze at Atmospheric Pressure", Trans. Am. Nucl. Soc., vol. 9(2), p. 573 . 1966 .

52. T. R. Bump. "Coolant Mixing in Fuel Subassemblies", Trans. Am. Nucl. Soc., vol. 9(2), pp. 571-572. 1966 .

53. D. R. MacFariane, R. O. Brittan (ANL) and A. Sesonske (Purdue). "An Analytic Study of the Transient Boiling of Sodium in Reactor Coolant Channels", Trans. Am. Nucl. Soc., vol. 9(1) pp. 289-290. 1965.

54. W. H. Arlt, R. N. Duncan, T. J. Pashos, and P. W. Mathay. "Recent Data on the Performance of Defected Low-Density Powder UO2 Fuels in Reactor Service", Trans. Am. Nucl. Soc., vol. 8(2), p. 365. 1965.

55. Robert C. Liimatainen (ANL), M. D. Freshiey (BNW), and Frank J. Testa (ANL). "Transient Irradiations of Vibrationally Compacted $\mathrm{UO}_{2}$ Fuel in TREAT", Trans. Am. Nucl. Soc., vol. 9(2), pp. 395-396. 1966.

56. J.H. Field and J. E. Hanson (GE-San Jose). "Response of High-Burnup Irradiated Plutonia-Urania Fuel to Transient overpower", Trans. Am. Nucl. Soc., vol. 9(2), pp. 396-397. 1966 . 
57. J. E. Hanson, J.H. Field, and S. A. Rabin. Experimental Studies of Transient Effects in Fast Reactor Fuels. Series II-Mixed Oxide (PuO2-UO2) Irradiations, GEAP-4804. June 1965. Also see paper by S. A. Rabin, W. E. Baily, J. E. Hanson, and F. W. Knight. "Mixed oxide Fuel Movement at Various Power Levels and in Transients", Proceedings of the Conference on Safety, Fuels, and Core Design in Large Fast Power Reactors, ANL-7120. p. 524-533. October 1965.

58. C. E. Dickerman (ANL). "Use of Present TREAT Core as a Fast-Flux Loop-Meltdown Facility", Trans. Am. Nucl. Soc., vol. 9(2), p. 551. 1966 .

59. R. C. Liimatainen and F. J. Testa. "Thermal-Reactor Safety Studies on U02 Core Fuel-Pin Clusters: Transient Meltdowns", Trans. Am. Nucl. Soc., vol. 9(2), pp. 561-562. 1966 .

60. C. E. Dickerman, L. E. Robinson, and R. Stewart (ANL). "Photographic TREAT Fast-Reactor Safety Experiments on Irradiated-oxide Pins", Trans. Am. Nucl. Soc., vol. 9(2), p. 396. 1966 .

61. Ralph G. Chalker (AI). "A Critical Review of Nuclear Codes and Standards Avaizable and Under Development in the United States", Trans. Am. Nucl. Soc., vol. 9(2), pp. 408-409. 1966 .

62. A. B. Reynolds and S. L. Stewart (GE-San Jose). "Analysis of SEFOR Mockup in ZPR-III", Trans. Am. Nucl. Soc., vol. 9(1), p. 227, 1965.

63. R. H. Chastain and H. I. Sternberg (WAPD). "Predicted and observed Performance of the Saxton Partial Plutonium Core During Startup Tests", Trans. Am. Nucl. Soc., vol. 9(1), pp. 280-281. 1965 .

64. L. E. Strawbridge, F. M. Heck, and W. E. Gunson. "Safety Considerations in the Design of Large Fast-Breeder Reactors", Trans. Am. Nucl. Soc., vol. 9(2), p. 546. 1966.

65. T. R. Bump and W. R. Simmons. "Hold-Down Requirements for Poison Control Rods", Trans. Am. Nucl. Soc., vol. 9(2), p. 597. 1966 .

66. M. J. Whitman (USAEC). "Comments on Reactor Fuel for FFTF," Letter to FFTF. September $28,1965$. 
67. L. J. Anastasia, P. G. Alfredson, and M. J. Steindler. "Flourination of $\mathrm{UO}_{2}-\mathrm{PuO}_{2}$ Fission-Product oxide Pellets in a Fluidized-Bed Reactor", Trans. Am. Nucl. Soc., vol.8(2), pp. $357-358 . \quad 1965$.

68. E. Duncombe, J. E. Meyer, and W. A. Coffman (W-BAPL). "Comparison with Experimental of Calculated Dimension Changes and Failure Analysis of Irradiated Bulk-Oxide Fuel Test Rods Using the CYGRO-I Computer Program", Trans. Am. Nucl. Soc., vol. $9(2)$, pp. 373-374. 1966 .

69. W. Kermit Anderson and Gerhard o. MueZzer (KAPL). "Thermal Calculations for Cylindrical Fuel Rods Based on the Robertson Concept", Trans. Am. Nucl. Soc., vol. 9(2), pp. 374-375. 1966 .

70. G. J. Moyar, E. F. Koenig, G. L. Lechliter, and W. Kermit Anderson (KAPL). "NUKER: A Program for Thermal and Mechanical Analysis of Fuel Rods", Trans. Am. Nucl. Soc., vol. 9(2), pp. $379-380$. 1966 .

71. J. E. Barnes, Jr. and G.J. Moyar (KAPL). "Computer Model of the Rheological Properties of Nuclear Fuels", Trans. Am. Nucl. soc., vol. 9(2), p. 381. 1966.

72. Benjamin M. Ma (ISU). "Irradiation Growth and SwelZing Analysis for Finite Cylindrical Fuel Elements", Trans. Am. Nucl. Soc., vol. 9(1), p. 67. 1965.

73. A. C. Batten and C. R. Johnson. "Gas Permeability of Vibratory Compacted UO $2^{\prime \prime}$, Trans. Am. Nucl. Soc., vol. 9(2), p. 393. 1966 .

74. D. R. de HaZas. "Cermet and Oxide Fuels Review", Fast Flux Test Facility Driver Fuel Meeting, BNWL-268. June 1966. 


\section{DISTRIBUTION}

No. of

Copies

2

AEC Chicago Patent Group

G. H. Lee, Chief

R. K. Sharp, Richland

1 AEC Idaho Operations Office

Nuclear Technology Division

C. W. Bills, Director

30 $\frac{\text { AEC Library, Washington, D.C. }}{\text { Division of Reactor Dev \& Tech }}$

M. Shaw, Director, RDT

Asst. Dir. for Nuclear Safety

Analysis \& Evaluation Br., RDT:NS

Environmental \& Sanitary Engrg. Br., RDT:NS

Research \& Development Br., RDT:NS

Asst. Dir. for Plant Engrg., RDT

Applications \& Facilities Br., RDT:PE

Components $\mathrm{Br}$, RDT:PE

Instrumentation, \& Control Br., RDT:PE

Systems Engineering $\mathrm{Br}$., RDT:PE

Asst. Dir. for Program Analys is, RDT

Asst. Dir. for Project Mgmt., RDTT

Liquid Metals Projects Br., RDT:PM

FFTF Project Manager, RDT:PM (3)

Asst. Dir. for Reactor Engrg.

Control Mechanisms Br., RDT:RE

Core Design Br。, RDT:RE (2)

Fue 1 Fabrication Br., RDT:RE

Fuel Handling Br., RDT:RE

Reactor Vessels $\mathrm{Br}$, RDT:RE

Asst. Dir. for Reactor Tech.

Chemistry \& Chemical Separations

$\mathrm{Br}$, RDT:RT (2)

Fue 1s \& Materials Br., RDT:RT

Reactor Physics Br., RDT:RT

Special Technology Br., RDT:RT

Asst. Dir, for Engrg. Standards

3 AEC Richland Operations Office

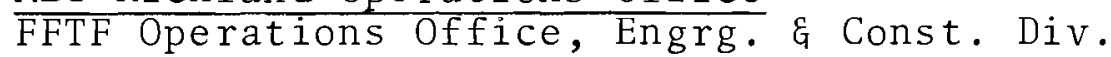

J.M.Shivley 
No. of

Copies

1

4

2

2

2

1
AEC San Francisco Operations Office Director, Reactor Division

2111 Bancroft Way

Berkeley, California 94704

AEC Site Representatives - PNL

P. G. Holsted (2)

L. R. Lucas

A. D. Toth

AEC Site Representatives

Argonne National Laboratory

Atomics International

Atomic Power Development Assoc.

General Electric Co.

310 Deguigne Drive

Sunnyvale, California 94086

Argonne National Laboratory

R. A. Jaross

LMFBR Program Office

Atomics International

L. E. Glasgow

Liquid Metal Engrg. Center

R. W. Dickinson

Atomic Power Development Assoc.

B. V. D. Farris

Babcock \& Wilcox Co.

Atomic Energy Division

5061 Fort Avenue

Lynchburg, Virginia 24505

S. H. Esleeck

Boiler Division

Sterling Avenue

Barberton, Ohio 44203

T. P. Farre11

Combustion Engineering

1000 MWe Follow-On Study

P. O. Box 500

Windsor, Connecticut 06905

W. P. Staker, Project Manager 
No. of

Copies

2

General Dynamics Corp.

P. O. Box 608

San Diego, California 92112

D. Coburn

4

General Electric Co.

Advanced Products Operation

310 Deguigne Drive

Sunnyvale, California 94086

Kar1 Cohen (3)

Bertram Wolfe

1

Idaho Nuclear Corporation

P. O. Box 1845

Idaho Fa11s, Idaho 83401

D. R. deBoisblanc

1

1

. A. Hill (ZPR III)

Stanford University

Nuclear Division

Division of Mechanical Engrg.

Stanford, California 94305

R. Sher

5

Westinghouse Electric Corp.

Atomic Power Division

Advanced Reactor Systems

Waltz Mill Site

P. 0. Box 158

Madison, Pennsylvania 15663

J. C. R. Ke11y

71

Battelle-Northwest

$H . J$. Anderson

R. J. Anicetti

E. R. Astley

W. J. Bailey

R. E. Bardsley

J. A. Basmajian

J. M. Batch

T. Bauman

A. L. Bement 
No. of

Copies

Batte11e-Northwest (contd)

T. J. Bennett

D. F. Bloomfield

C. L. Boyd

C. A. Burgess

T. B. Burley

J. J. Cadwe11

W. E. Cawley

T. D. Chikalla

J. A. Christensen

P. D. Cohn

D. L. Condotta

R. M. Crawford

R. G. Curran

J. M. Davidson

E. A. Evans

T. W. Evans

P. L. Farnsworth

L. M. Finch

G. L. Fox

M. D. Freshley

E. E. Garrett

S. Goldsmith

R. L. Gulley

W. L. Hampson

J. E. Hanson

B. R. Hayward

P. L. Hofmann

G. R. Horn

R. J. Jackson

D. C. Kolesar

D. C. Lehfeldt

R. J. Lobsinger

W. B. McDonald

K. R. Merckx

M. K. Millhollen

R. E. Nightingale

L. A. Pember

H. G. Powers

W. A. Richmond

W. E. Roake

R. K. Robinson

D. E. Simpson

R. C. Smith

R. J. Squires

E. G. Stevens

C. D. Swanson

H. A. Taylor 
No. of

Copies

Battelle-Northwest (contd)

J. Thornton

J. C. Tobin

J. H. Westsik

D. R. Wilson

H. R. Wise $1 y$

N. G. Wittenbrock

F. W. Woodfield

FFTF Record File

FFTF Reference File

Technical Information Files

(5)

Technica1 Pub1ications 